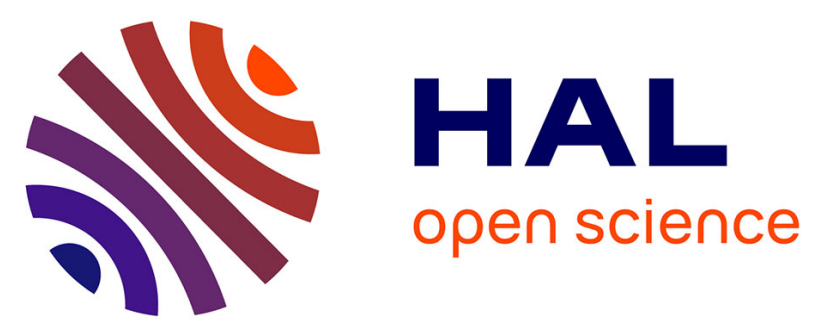

\title{
Efficacy of zinc salts to protect glass against atmospheric alteration. Part I: Effects of a spraying treatment
}

\author{
Fanny Alloteau, Odile Majérus, Valentina Valbi, Isabelle Biron, Patrice \\ Lehuédé, Daniel Caurant, Grégory Lefèvre, Antoine Seyeux
}

\section{- To cite this version:}

Fanny Alloteau, Odile Majérus, Valentina Valbi, Isabelle Biron, Patrice Lehuédé, et al.. Efficacy of zinc salts to protect glass against atmospheric alteration. Part I: Effects of a spraying treatment. Journal of the American Ceramic Society, 2021, 104 (5), pp.2039 - 2051. 10.1111/jace.17590 . hal-03379563

\section{HAL Id: hal-03379563 https://hal.science/hal-03379563}

Submitted on 15 Oct 2021

HAL is a multi-disciplinary open access archive for the deposit and dissemination of scientific research documents, whether they are published or not. The documents may come from teaching and research institutions in France or abroad, or from public or private research centers.
L'archive ouverte pluridisciplinaire HAL, est destinée au dépôt et à la diffusion de documents scientifiques de niveau recherche, publiés ou non, émanant des établissements d'enseignement et de recherche français ou étrangers, des laboratoires publics ou privés. 
Efficacy of zinc salts to protect glass against atmospheric

\author{
alteration. Part I: Effects of a spraying treatment.
}

Fanny Alloteau* ${ }^{* 1,2}$, Odile Majérus ${ }^{2}$, Valentina Valbi ${ }^{\ddagger 1,2}$, Isabelle Biron ${ }^{1}$, Patrice Lehuédé $^{1}$, Daniel Caurant ${ }^{2}$, Grégory Lefèvre ${ }^{2}$ and Antoine Seyeux ${ }^{2}$

${ }^{1}$ Centre de Recherche et de Restauration des Musées de France, PSL Research

University, CNRS, Institut de Recherche de Chimie Paris (IRCP), F-75001 Paris,

France

${ }^{2}$ Chimie ParisTech, PSL Research University, CNRS, Institut de Recherche de Chimie Paris (IRCP), F-75005 Paris, France

\begin{abstract}
Following an industrial process to protect manufactured glass windows against atmospheric corrosion during their storage and transport, this research is focused on the possibility that a surface deposit of a small amount of zinc salts may efficiently reduce the atmospheric alteration kinetics of ancient

\footnotetext{
*corresponding author - alloteau.fanny@gmail.com

${ }^{\dagger}$ current affiliation: Rathgen-Forschungslabor, Staatliche Museen zu Berlin - Stiftung Preußischer Kulturbesitz (SMB-

${ }^{\ddagger}$ current affiliation: Laboratoire Géomatériaux et Environnement (LGE) - Université Gustave Eiffel, F-93160 Noisy-Le-
} SPK), Berlin Grand, France
\end{abstract}

This article has been accepted for publication and undergone full peer review but has not been through the copyediting, typesetting, pagination and proofreading process, which may lead to differences between this version and the Version of Record. Please cite this article as doi: 10.1111/JACE. 17590

This article is protected by copyright. All rights reserved 
glasses (soda, potash and mixed alkali silicates). To this purpose, the chemical action of zinc salts was investigated by means of ageing experiments (with temperature and relative humidity $(\mathrm{RH})$ control) on three glass models, of which compositions are representative of the cultural heritage. When the treatment was performed on pristine glass (about $1 \mu \mathrm{g} / \mathrm{cm}^{2}$ of deposited $\mathrm{Zn}^{2+}$ ions), treated glass plates developed a significantly thinner hydrated layer than the untreated ones at $80^{\circ} \mathrm{C}$ or at $40^{\circ} \mathrm{C}(85 \mathrm{RH} \%)$. The formation of alkali and Ca-carbonates salts on the surface was also considerably reduced. The state of the glass surface undergoing the $\mathrm{Zn}$ treatment and the temperature of the treatment seem critical regarding the efficacy of the protection.

\section{INTRODUCTION}

Depending on their compositions and their conditions of conservation, a significant proportion of ancient glasses in museums (glass objects, enamels and glazes) show the signs of a chemical and physical degradation induced by moisture attack, so-called atmospheric alteration of glass, a specific manifestation of glass corrosion induced by unsaturated relative humidity $(\mathrm{RH}<100 \%) \cdot{ }^{1-5}$ In the museum collections of Western Europe for instance, this active degradation is noticeable on the surface of about 10 to $20 \%$ of the glass objects, ${ }^{6-8}$ mainly glass objects produced since the Middle-Ages when glassmakers employed new raw materials and new raw material purification processes. ${ }^{9,10}$ Considering that the manifestations of the degradation on the surface are often not visible to the naked eyes, the atmospheric alteration may possibly affect even many glass objects in museums. White salt deposit, weeping, crizzling and flaking (Fig. S1 in Supplemental Materials, section S3) are the main well-known symptomatic manifestations on glass surface. Besides affecting the reading of the artwork, this can result on loss of material at a late stage, when glass flakes are formed and pulled away from the surface. ${ }^{3,11}$

Until now the best protective measure to slow down this atmospheric alteration in museums is the washing off newly formed salts on glass surface ${ }^{4,6,7,12}$ and the environment control (temperature, relative humidity, 
pollutants) within suitable museum display cases. ${ }^{1,3,4,12-15}$ Nevertheless, by acting directly on the glass surface, more efficient and less costly protective methods should be considered. In accordance with the museum context, such a method must be:

- Non-toxic,

- Respectful of the mechanical, chemical and optical integrity of the glass artefact,

- Reversible, as far as possible,

- Limited in the amount of applied material,

- Easily handled with a reasonable application frequency for the museums,

- Inexpensive and readily available.

Previously investigated or even applied external chemical treatments for the protection of ancient glasses of the cultural heritage mainly consisted of more or less adherent coatings to act as a protective barrier against moisture. ${ }^{2,4,16-24}$ But for reasons of limited performance and lack of reversibility, the majority of these coatings - in particular those involving resins - seems to have been progressively abandoned except for consolidation purposes. On the contrary, adherent silica-based coatings have been developed in the last decades. These coatings consist either of inorganic-organic sol-gels functionalized with hydrophobic polymers or of pure silica sol-gels, and are applied with or without thermal treatment. ${ }^{21-24}$ The thickness of these deposits, a few hundred nanometers, and the good chemical compatibility between the coating and the glass reduce the physical stresses, but the efficacy of the treatment on altered glasses seems to be still under evaluation.

An interesting alternative approach consists of applying an external chemical treatment in order to chemically stabilize the glass surface and thus slow down the alteration kinetics. In this perspective, our study focusses on the potential of a protective treatment based on the deposit of a very small amount of zinc salts on the surface of chemically unstable ancient glasses. The idea of this treatment stems from 
industrial applications based on empirical approaches, namely the use of small amounts of zinc salts to protect soda-lime silicate glass in an industrial context, either against the atmospheric alteration of freshly produced flat glass during their transport and storage, ${ }^{25-29}$ or against the silicate network dissolution of glassware during washing in dishwasher. ${ }^{30-33}$ In the first application in particular, a diluted aqueous solution of zinc salts is sprayed on glass surface at the end of the float process, when the temperature of the glass surface approaches $60^{\circ} \mathrm{C}$. The washing of the deposit is performed some weeks or months later, prior to surface coating or transformation by the client.

To evaluate the action and the relevance of a treatment based on zinc salts for glass artefacts of the cultural heritage, experiments were conducted on the basis of a treatment adapted to the museum context and applied to three glass replicas, the compositions of which are representative of ancient glasses, specifically soda, potash and mixed alkali silicates. These glass compositions have distinct chemical durabilities: two are unstable with respect to the atmospheric alteration and one is stable..$^{5,34,35}$ The effects of the zinc treatment on the phenomenology of atmospheric alteration were studied by performing comparative accelerated ageing tests (temperature and $\mathrm{RH}$ control) of untreated and treated glass plates. These effects on freshly polished glass surfaces are the main subject of this paper. Preliminary results dealing with these effects, when the treatment is performed on previously altered surfaces, are also presented. All the accelerated ageing tests were performed under climatic conditions that prevent any water runoff on glass surface and in neutral atmosphere (without any acidic pollutants coming from the materials involved in the storage and display case conditions in the museum environment), which represent the best laboratory conditions to study the effects of the atmospheric alteration. Two different temperatures $\left(40^{\circ} \mathrm{C}\right.$ or $\left.80^{\circ} \mathrm{C}\right)$ were chosen for the ageings to accelerate the kinetics of alteration, thus making the study possible within a reasonable timescale, and to estimate the temperature effect on the treatment performances considering that this parameter has a significant influence on the glass alteration mechanisms. ${ }^{36}$ Beyond the context of the conservation of cultural heritage ancient glass, this study is the first, to our knowledge, to give an extended and multiscale description of the effects of the deposition of zinc salts on the glass surface. 
The chemical speciation of the $\mathrm{Zn}^{2+}$ ions and their transformation with the atmospheric alteration are detailed in a second article (part $\mathrm{II}^{37}$ ), in which the possible mechanisms of the passivation are thoroughly discussed.

\section{EXPERIMENTAL PROCEDURES}

\subsection{Glass sample preparation}

Experiments were performed on three alkali-rich silicate glasses, referred to as A, SL and $\mathbf{P}$. Their respective compositions, as detailed in Table 1, were chosen to be representative of one or more productions of glass artefacts, displaying various degrees of atmospheric alteration. ${ }^{5,11,34,35}$ In particular, the significantly better chemical durability of glass SL under atmosphere, whose composition exhibits a higher $\mathrm{Na}_{2} \mathrm{O} / \mathrm{K}_{2} \mathrm{O}$ ratio and a higher content in alkaline earth oxides (so-called stabilizers) and in alumina as compared to glasses $\mathbf{A}$ and $\mathbf{P}$, has been highlighted in a parallel study dealing with the composition effects on the mechanisms of glass atmospheric alteration. ${ }^{38}$ Batches of $1 \mathrm{~kg}$ of each of these glass replicas were elaborated by Saint-Gobain Recherche (France) according to the procedure described in Ref., ${ }^{39}$ and their compositions were checked by chemical analysis (discrepancies were far below $1 \%$ for every oxide). Samples were prepared in the form of plates $\left(1 \times 1 \times 0.3 \mathrm{~cm}^{3}\right)$ polished on one side with an aqueous suspension of a commercial $\mathrm{CeO}_{2}$ powder (grain size of $1 \mu \mathrm{m}$ ) by an external company (Opa Opticad, France). In this study the repeatable polishing procedure was chosen to minimize glass surface defects prior to the zinc treatment and the ageing test, and to perform surface analysis techniques that require as much as possible flat and smooth surfaces. Shortly before the surface treatment with zinc salts and the ageing tests, the polished plates were thoroughly cleaned with sodium dodecyl sulfate (SDS) $1 \mathrm{M}$ to remove organic dirt, rinsed with milliQ water and then ultrasonically cleaned in ethanol during 10 min. Samples were then dried during $5 \mathrm{~s}$ with an air flux $\left(\mathrm{T} \leq 40^{\circ} \mathrm{C}\right)$. Tof-SIMS analysis conducted on dedicated glass plates after these preparation steps showed an outermost surface layer of about $30 \mathrm{~nm}$ that 
is partially alkali depleted (Fig. $2.2 \mathrm{~b}$ in Ref. ${ }^{39}$ ).

\subsection{Zinc salt deposit on glass surface - protocol and quantification}

In view of the application in the museum context, a zinc salt spraying treatment was carried out at room temperature on glass plates. Reagent grade zinc chloride $\left(\mathrm{ZnCl}_{2}\right.$, Fluka Chemica) or zinc nitrate hexahydrate $\left(\mathrm{Zn}\left(\mathrm{NO}_{3}\right)_{2} \cdot 6 \mathrm{H}_{2} \mathrm{O}\right.$, Sigma-Aldrich) was diluted in absolute ethanol at room temperature to obtain $\mathrm{Zn}^{2+}$ ion concentrations in solution of $0.61 \mathrm{mM}$ up to $9 \mathrm{mM}$. Zinc citrate dihydrate $\left(\left(\mathrm{C}_{6} \mathrm{H}_{5} \mathrm{O}_{7}\right)_{2} \mathrm{Zn}_{3} \cdot 2 \mathrm{H}_{2} \mathrm{O}\right.$, Sigma-Aldrich $)$, a salt far less soluble in ethanol than its chloride and nitrate counterparts, was alternatively used for comparison purposes. Pluronic F-127 (BASF), a low-foaming non-ionic surfactant, was added at a concentration of about $0,015 \mathrm{~g} / \mathrm{L}$ to the solutions for its wetting action. Note that no positive effect of the surfactant against atmospheric alteration was observed (experiments not detailed). By means of a commercial sprayer, this zinc salt ethanolic solution was manually sprayed on the polished side of glass plates freshly cleaned: a continuous film, that evaporates very quickly, was observed on the surface in the laboratory atmosphere at room temperature. In order to quantify the amount of $\mathrm{Zn}^{2+}$ deposited on the surfaces, sensitive and accurate methods were selected: either spatially unresolved (Particle Induced X-Ray Emission (PIXE), Energy Dispersive X-Ray Fluorescence Spectroscopy (EDXRF)) or spatially resolved (Scanning Electron Microscopy - Energy Dispersive X-Ray Spectroscopy (SEM-EDX)). Details about the apparatus and the optimized operating conditions are given in the Supplemental Materials, section S1.1. In this paper, the amount of zinc on the glass surface is systematically expressed in weight concentration per unit area $\left(\mathrm{\mu g} / \mathrm{cm}^{2}\right)$ of $\mathrm{Zn}^{2+}$ ions. With our spraying treatment, the concentration of $\mathrm{Zn}^{2+}$ ions on the glass surface varied from $0.1 \pm 0.031 \mathrm{\mu g} / \mathrm{cm}^{2}$ to $1.5 \pm 0.11 \mu \mathrm{g} / \mathrm{cm}^{2}$, depending on the concentration of the spraying solution. The spraying treatments used in this study, according to the $\mathrm{Zn}^{2+}$ ions concentration on glass surface, are summarized in Table S1 (Supplemental Materials, section S3). 


\subsection{Evaluation of the protective action of the zinc salts treatment against atmospheric glass alteration}

Effects of the zinc salt treatment on glass atmospheric alteration were studied by simultaneously ageing untreated and treated glass plates. For every ageing experiment (natural ageing or accelerated ageing with a specific T, $\mathrm{RH} \%$, total period), at least the 3 glass compositions were tested with the zinc treatment of highest concentration at least (referred to as ZP__1.5 in the Table S1 of the Supplemental Materials, and corresponding to a surface concentration in $\mathrm{Zn}^{2+}$ ions of about $1.5 \mu \mathrm{g} / \mathrm{cm}^{2}$ ) based on zinc nitrate hexahydrate. Additional samples aiming in particular at evaluating the effect of the nature of the zinc salts and of the $\mathrm{Zn}^{2+}$ concentration on glass surface could be added for some of these ageing experiments. To test the reproducibility, each sample was duplicated for each ageing experiments. Zinc treatments were performed shortly before an ageing test, either on non-altered and freshly cleaned glass plates, or on pre-altered glass plates. The surface and near-surface modifications, after the zinc salt treatment and after the ageing test, were compared in terms of morphology (surface aspect, nature and amount of the precipitates, alteration layer thickness) and chemical composition.

\subsubsection{Ageing tests}

Glass plates, put horizontally with the polished side upwards, were submitted to atmospheric ageing tests (i.e. without any condensation) at $40^{\circ} \mathrm{C}$ or $80^{\circ} \mathrm{C}, 85 \mathrm{RH} \%$, over various time periods - from one day to several months - or during 2 years in the ambient atmosphere of the laboratory, protected from the dust. Regarding the accelerated ageing tests at $40^{\circ} \mathrm{C}$ or $80^{\circ} \mathrm{C}, 85 \mathrm{RH} \%$, two different devices were used in parallel to simultaneously control the relative humidity and the temperature of the ageing atmosphere: [i] a climatic chamber (details about the device is given in Ref. ${ }^{40}$ ) and [ii] a hermetic box in acrylic resin, for the $\mathrm{V}$ tests at $40{ }^{\circ} \mathrm{C}$ exclusively, put into an oven and containing a saturated saline solution of $\mathrm{KCl}$. According to Greenspan, the relative humidity in these experimental conditions is close to $82,5 \%{ }^{41}$ The climatic conditions (program of temperature and $\mathrm{RH}$ ) were carefully chosen to avoid any condensation 
onto the samples during the test. All accelerated ageing tests were performed in static mode (no cycling). In this paper, they are noted V tests or VXd or VXm tests, where X is the total period in days (d) or months $(\mathrm{m})$ including the ramps (3 hours each). Temperature and relative humidity were measured at samples positions by using external sensors (MadgeTech data logger PRHTemp101A) and were close to the set values within $\pm 0.5{ }^{\circ} \mathrm{C}(\mathrm{T})$ and $\pm 3 \%(\mathrm{RH})$. In particular for the device [ii], the measured $\mathrm{RH}$ was actually $85 \% \pm 3 \%$. The good correspondence between the two ageing methods (devices [i] or [ii]) was checked by comparing results with a 2 -months ageing test at $50{ }^{\circ} \mathrm{C}, 85 \mathrm{RH} \%$, for glass $\mathbf{A}$, in terms of alteration layer thickness and nature of neoformed surface salts. Note that for every experimental condition, a new sample was created and aged. At the end of an ageing test, glass plates were left in laboratory atmosphere at room temperature, protected from the dust. Regarding these aged samples, and the samples that have been aged for 2 years in the ambient atmosphere of the laboratory, the $\mathrm{T}$ and $\mathrm{RH} \%$ conditions have been monitored using a same MadgeTech data logger (average temperature: $22.2^{\circ} \mathrm{C}$; average $\mathrm{RH}: 40.6 \%$ over a one-year period).

\subsubsection{Characterization methods}

Sample preparation before characterization was intentionally very limited. Notably, no rinsing nor polishing was performed, because these operations may be harmful to the integrity of the alteration layers. ${ }^{40}$ Thus, the surfaces of the aged samples were in some cases covered with salt deposits and analytical methods compatible with these constraints were employed for the characterization. Note that the characterizations after an accelerated ageing test were performed shortly after the end of the test and could then be repeated at several time intervals over a 6 months period for a same glass plate, because certain aged glass surfaces continued to transform under the laboratory atmosphere. ${ }^{40}$

\section{Glass surface states}

The surface states of the glass plates were characterized by optical microscopy in direct or grazing light and by electronic microscopy with a Field Electron Gun Scanning Electron Microscope (FEG-SEM, 
JEOL $7800 \mathrm{~F}$ ) instrument, preferentially in secondary electron mode at low accelerating voltage (2 to $7 \mathrm{kV}$ ), after making the glass surface conductive with a platinum deposit about $1 \mathrm{~nm}$ thick. For the platinum layer deposition and the SEM observation, samples were submitted to a vacuum of about $1 \mathrm{~Pa}$ and $5.10^{-5} \mathrm{~Pa}$ respectively.

\section{Thickness of alteration layers}

The thickness of alteration layers, referred to as $\mathrm{e}_{a}$ in this paper, were determined either by TofSIMS ( $\mathrm{e}_{a}$ from some tens of $\mathrm{nm}$ to about $200 \mathrm{~nm}$ ) or by SEM $\left(\mathrm{e}_{a}>200 \mathrm{~nm}\right)$ analysis. Details about the operating conditions of the Tof-SIMS V instrument (Ion-Tof company) and the assessment of $\mathrm{e}_{a}$ by Tof-SIMS analysis are given in Ref. ${ }^{36}$ and in the Supplemental Materials, section S1.2. Regarding the determination of $\mathrm{e}_{a}$ by SEM observations, when flakes formed on glass plates, their thickness was measured and associated with the alteration layer thickness after checking that the flaking had indeed occurred near the interface between the alteration layer and pristine glass. Otherwise, SEM observations were performed on the edge, on a freshly fractured plate, preferentially in backscattered electron mode to visualize the chemical contrast at the interface. These observations were performed in different areas of a same aged glass plate and we give the average thickness $\mathrm{e}_{a}$.

\section{Chemical analysis}

Chemical elementary compositions of the alteration layers were quantified by EDX with the Bruker QUANTAX 400 system, at the same time as SEM observations. Analyses were performed on the glass plate surface, away from any defect or crystal, according to the operating conditions and the specific quantification method described in Ref. ${ }^{40}$ and in the Supplemental Materials, section S1.3. In particular for the treated glass plates and/or when the alteration layer thickness was smaller than the analysis depth, stacks of different layers (a $\mathrm{ZnO}$ layer on the top of an alteration layer and/or a pristine glass below an alteration layer) were modeled in the STRATAGem data processing software (SAMx company) to take into account the matrix effects (Phi-Rho-Z correction). Chemical composition profiles of the alteration 
layers, from the glass plate surface to the alteration layer-pristine glass interface, were obtained by TofSIMS analysis (operating conditions given in Ref. ${ }^{36}$ and in the Supplemental Materials, section S1.2). Chemical characterization of the salt deposits on the surface of glass plates was performed by EDX at low accelerating voltage, by XRD with an X'Pert PRO PANalytical instrument using $\mathrm{Cu}-\mathrm{K}_{\alpha}$ radiation, and by micro-Raman spectroscopy with a Renishaw Invia instrument using a $532 \mathrm{~nm}$ solid-state laser as excitation light.

\section{Hydration level measurement}

The amount of water in the hydrated layer, or hydration level noted HL in this article, was measured on glass plates by EDX according to the original method described in Ref. ${ }^{40}$ and in the Supplemental Materials, section S1.3. This local measurement corresponds to the water content that is not evaporated under vacuum, i.e. to the tightly bound water.

\section{RESULTS}

Results are detailed for the treatment of highest concentration ZP_1.5 performed on pristine glass plates that were freshly polished and cleaned. Complementary experiments including a pre-ageing step before treatment are presented in the last paragraph of this section. Additional experimental results dealing with the effects of the treatment concentration and of the nature of zinc salts are reported in the Supplemental Materials (section S2).

\subsection{Chemical and microstructural aspect of the treatment before ageing}

To the naked eye, the spraying treatment $\mathbf{Z P} \_\mathbf{1 . 5}$ did not modify the visual aspect of the glass plate surfaces, whatever the composition of the glass replica $(\mathbf{A}, \mathbf{S L}$ or $\mathbf{P})$. At a smaller scale, an almost immediate surface precipitation was observed during the first hour after the treatment. The distribution of the precipitates appeared homogeneous on a $10 \mu \mathrm{m}$ scale with a treatment based on zinc nitrate hex-

This article is protected by copyright. All rights reserved. 
ahydrate or zinc chloride (Fig. S2c in the Supplemental Materials section S3, for the $\mathbf{Z P} \_\mathbf{1 . 5}$ treatment based on $\left.\mathrm{Zn}\left(\mathrm{NO}_{3}\right)_{2} \cdot 6 \mathrm{H}_{2} \mathrm{O}\right)$. For a given zinc salt in the spraying solution, the morphology of the precipitation is comparable for the 3 glass replicas. With the treatment using $\mathrm{Zn}\left(\mathrm{NO}_{3}\right)_{2} \cdot 6 \mathrm{H}_{2} \mathrm{O}$, Na and $\mathrm{K}$ nitrate salts were identified (numbered respectively [2] and [3] in Fig. S2c), together with zinc hydroxide nitrate $\mathrm{Zn}_{5}(\mathrm{OH})_{8}\left(\mathrm{NO}_{3}\right)_{2} \cdot 2 \mathrm{H}_{2} \mathrm{O}$ (numbered [1] in Fig. S2c), as identified by XRD and micro-Raman spectroscopy. With the treatment using $\mathrm{ZnCl}_{2}, \mathrm{Na}$ and $\mathrm{K}$ chloride salts were identified on the glass surface, together with simonkolleite $\mathrm{Zn}_{5}(\mathrm{OH})_{8} \mathrm{Cl}_{2} \cdot 2 \mathrm{H}_{2} \mathrm{O}$. The formation of $\mathrm{Na}$ and $\mathrm{K}$ nitrate resp. chloride salts on the glass surface is related to the reaction of the $\mathrm{Zn}^{2+}$ counter-ion $\left(\mathrm{NO}_{3}^{-}\right.$resp. $\left.\mathrm{Cl}^{-}\right)$with alkalis coming from the outermost surface layer of the glass plate. According to Tof-SIMS analysis, the alkali depletion stays limited within about $50 \mathrm{~nm}$ with the $\mathbf{Z P} \_\mathbf{1 . 5}$ treatment (orange curves in Fig. 6.14 in Ref. ${ }^{39}$ for a treatment based on $\left.\mathrm{Zn}\left(\mathrm{NO}_{3}\right)_{2} \cdot 6 \mathrm{H}_{2} \mathrm{O}\right)$.

It is worth mentioning that $\mathrm{Zn}^{2+}$ ions were systematically detected on the glass surface outside of any $\mathrm{Zn}$ precipitates. The $\mathrm{Zn}^{2+}$ concentration outside the Zn-bearing precipitates was around $0.1 \mathrm{\mu g} / \mathrm{cm}^{2}$ (SEMEDX analysis, see the Supplemental Materials section S1.1.1). Furthermore, the study of the effect of the treatment concentration, which highlights distinct morphologies of precipitation according to the amount of deposited $\mathrm{Zn}^{2+}$ ions on glass surface, shows that the sorbed $\mathrm{Zn}^{2+}$ ions were mainly located on the outer surface (see the Supplemental Materials, section S2.2). The chemical reactions underlying the surface sorption of $\mathrm{Zn}^{2+}$ ions or their precipitation with hydroxides are given and discussed in the Part II article. ${ }^{37}$

\subsection{Effects of the treatment with the ageing}

During the accelerated ageing test, the reactions of the glass with the humidity and acid gas $\left(\mathrm{CO}_{2}\right)$ produce a superficial alteration layer of variable thickness. Generally, this alteration layer is composed of two sub-layers: [i] a bottom layer at the interface with the pristine glass, which is strongly hydrated and partially, variably, alkali depleted. This layer is called the hydrated layer in this article. [ii] A top 
layer at the interface with the atmosphere, consisting of alkali salts formed by the acid-base reaction of alkali hydroxide with acid gas (carbonates in our case). This top layer may be almost absent, when the alkalis are strongly retained in the hydrated layer (as it is the case for glass $\mathbf{A}$ aged at $80^{\circ} \mathrm{C}, 85 \mathrm{RH} \%$ for instance ${ }^{40}$ ), or it may exist as a thick crust of salts when alkalis are strongly driven out of the hydrated layer (as for glass $\mathbf{S L}$ aged at $40^{\circ} \mathrm{C}, 85 \mathrm{RH} \%^{39}$ ). This layer is named "top layer" or "salt layer" in this article.

When the glass plates were treated with the zinc salts before the accelerated ageing, the extent of the reactions of the glass with the atmosphere was generally significantly reduced. Notably, the thickness of the hydrated layer was smaller and the formation of alkali and Ca-carbonates was considerably inhibited. These results are described for glass $\mathbf{A}$ in details, then for glasses $\mathbf{S L}$ and $\mathbf{P}$ to address the influence of the glass composition.

\subsubsection{Results on glass A}

The atmospheric alteration of untreated glass $\mathbf{A}$ has been thoroughly described in Ref. ${ }^{36,40}$ at $40{ }^{\circ} \mathrm{C}$ and at $80^{\circ} \mathrm{C}, 85 \mathrm{RH} \%$. The temperature has a dramatic effect on the alteration of this glass. In particular, the kinetics of the hydration of this glass is extremely high at $80^{\circ} \mathrm{C}$, with no dealkalization of the hydrated layer. At $40^{\circ} \mathrm{C}$, this kinetics is significantly reduced, with partial dealkalization and formation of Naand Ca-carbonates.

Surface state and nature of the precipitates

Following a $\mathrm{V}$ test at $80^{\circ} \mathrm{C}, 85 \mathrm{RH} \%$, and lasting 3 days, crizzling and flaking of the untreated glass surface occurred (Fig. 1a). ${ }^{40}$ Remarkably, with the $\mathbf{Z P} \_\mathbf{1 . 5}$ treatments, these manifestations were suppressed (Fig. 1b). Only Na and K chloride or nitrate according to the zinc salt counter-ion used for the treatment, and simonkolleite or Zn, N, O-rich phases respectively were identified on the treated and aged glass surfaces. Zinc precipitates transformed with the ageing in terms of morphology, distribution, 
and probably of composition. Notably, their surface density decreased, with less crystals per surface unit at the end of the ageing. Contrary to the untreated aged glass plates, which show progressive formation of carbonates on the surface during their storage under ambient atmosphere after the $\mathrm{V}$ test, the treated glass plates were stable after the ageing. By stable, we mean that the surface distribution of alkali- or Zn-bearing salts did not change and Na-carbonates did not form with time after the end of the ageing test.

Following an ageing at $40^{\circ} \mathrm{C}, 85 \mathrm{RH} \%$, and lasting 6 months, the untreated glass surface appeared crizzled and was covered by a thick crust of $\mathrm{Na}$ and Ca carbonates (Fig. 2a). ${ }^{36}$ The surface state of the treated glass plates appeared much better preserved with no signs of crizzling (Fig. 2b). Again, the distribution and microstructural aspect of the zinc precipitates (numbered [3] in Fig. 2b) transformed with the ageing, notably with a decrease of their surface density. A very few Na carbonates were identified but no Ca carbonates.

Regarding the result of the 2-years ageing under ambient atmosphere, no sign of crizzling but numerous precipitates were observed on the sufaces of both untreated and treated glass plates. By SEM-EDX, mainly Na carbonates and $\mathrm{K}$ sulphates were identified on the surface of the untreated ones. For the treated ones, the morphology of the zinc precipitates had clearly transformed with the ageing, and $\mathrm{C}$ element was systematically detected in the Zn-bearing precipitates. Na or K sulphates were also present on the surface of the treated glass plates.

\section{Alteration layer thicknesses}

The benefit of the treatment on the glass surface state is directly correlated to the considerable reduction of the alteration kinetics. Indeed, with an ageing at $80^{\circ} \mathrm{C}, 85 \mathrm{RH} \%$, for the three periods of ageing (1 day, 3 days or 6 days), the alteration layer thicknesses were reduced respectively by a factor of about 10, 60 or 100 (Fig. 3 and column $\mathrm{e}_{a}$ in Table 2). Moreover, the alteration kinetics appeared linear for the treated glass plates, unlike the untreated ones for which an acceleration of the alteration kinetics was 
observed. ${ }^{40}$ With an ageing at $40^{\circ} \mathrm{C}, 85 \mathrm{RH} \%$, the factors of reduction were about $1.5,8$ and 12 for the three periods of ageing 17 days, 3 months and 6 months respectively (Table 3 ), demonstrating that the hydration progressed in depth much more slowly with the treatment. By contrast, after 2 years of ageing under ambient atmosphere, no positive effect of the $\mathbf{Z P} \_\mathbf{1 . 5}$ treatment could be observed in term of alteration layer thickness: this thickness was about $150 \mathrm{~nm}$ for both the untreated and the treated glass plate.

\section{Composition and hydration level of the alteration layers}

Results of EDX analysis after $\mathrm{V}$ tests at $80^{\circ} \mathrm{C}, 85 \mathrm{RH} \%$ of untreated and treated glass plates are reported in Table 2. Whatever the nature of the zinc salt (chloride or nitrate), and the duration of the $\mathrm{V}$ test (1, 3 or 6 days), the composition of the alteration layers of the treated glass plates were similar: a depletion in $\mathrm{Na}$ of about $30 \%$ and in $\mathrm{K}$ of about $15 \%$ and a hydration level of about $6 \mathrm{wt} \%$ were evaluated in all cases (column Na/Si, K/Si and HL respectively in Table 2). We recall that the hydrated layers of the treated glass plates were considerably thinner than those of the untreated glass. Apart from this aspect, it is possible to compare the compositions of the hydrated layer in the treated and in the untreated cases. Noticeably, the composition of the hydrated layer of the treated glass, marked by a partial alkali depletion, was close to the composition of the hydrated layer of the untreated glass, after the latter glass had evolved and stabilized for several months under the ambient laboratory atmosphere. ${ }^{40}$

Concerning the $\mathrm{V}$ tests performed at $40^{\circ} \mathrm{C}, 85 \mathrm{RH} \%$, results of the EDX analysis are shown in Table 4 . For glass $\mathbf{A}$ aged at $40^{\circ} \mathrm{C}$ for 6 months, a slightly lower hydration level was measured in the alteration layer of the treated glass plates with respect to the untreated ones (column HL in Table 4). Moreover, while the depletion in $\mathrm{Na}$ increased slightly with the treatment (depletion of about $30 \%$ ), the depletion in Ca was inhibited with the treatment (column Na/Si and $\mathrm{Ca} / \mathrm{Si}$ respectively in Table 4), in accordance with the morphological observations of the glass surfaces, which did not reveal the presence of Ca-carbonates on the treated aged glass plates. 
Thus, the effects of the treatment are nearly the same at $80^{\circ} \mathrm{C}$ and at $40^{\circ} \mathrm{C}$ and independent of the nature of the zinc salts (see the Supplemental Materials, section S2.1 for more experimental results about the influence of the nature of the zinc salt). The kinetics of the hydration of the glass is considerably reduced, particularly at $80^{\circ} \mathrm{C}$ where the hydration of this glass is very fast and accelerating without treatment. ${ }^{40}$ As a consequence of the reduced hydration thickness, the amounts of Na- and Ca-carbonates on the surface are also considerably reduced.

\subsubsection{Influence of the glass composition}

Results in this section are described for the treatment of highest concentration $\mathbf{Z P} \_\mathbf{1 . 5}$ and for V tests performed at $40^{\circ} \mathrm{C}, 85 \mathrm{RH} \%$, for 3 or 6 months.

Surface state and nature of the precipitates

A benefit of the treatment on the glass surface states was observed for the 3 glass compositions after the ageings of 3 and 6 months. This visual benefit was more obvious for the glass compositions $\mathbf{A}$ and $\mathbf{S L}$ than for the glass $\mathbf{P}$, in relationship with the respective morphologies of alteration of these glasses when untreated: a significantly thicker salt layer is present on the surface of glasses $\mathbf{A}$ and $\mathbf{S L}$, compared with glass $\mathbf{P},{ }^{39}$ so that the diminution of the carbonate salts with the treatment was clearer. For glass $\mathbf{A}$, as described above, the treatment suppressed the crizzling phenomenon observed after 6 months of ageing and inhibited drastically the formation of Na- and Ca-carbonates (Fig. 2b as compared to Fig. 2a). For glass SL, crizzling was not observed for both the untreated and the treated surfaces after a 6 -month period of ageing. The treatment had considerably reduced the amount of precipitated phases on the glass surface, in particular no Ca-carbonates nor silica was observed contrary to the untreated surface (Fig. 2d as compared to Fig. 2c). For glass $\mathbf{P}$, like for glass $\mathbf{A}$, the crizzling phenomenon was suppressed with the 
treatment after the 6 months of ageing. For both untreated and treated glass plates, the salts on surfaces were deliquescent. Mainly Ca-, Na- and K-rich carbonates or sulphates were identified on the untreated surfaces. By contrast, on treated surfaces, no Ca- or Na- rich phases, but zinc precipitates (numbered [8] in Fig. 2f) containing possibly K were identified. Furthemore, the thin continous layer of precipitates that covered almost entirely the surface of the untreated glass (numbered [7] in Fig. 2e, nature unidentified) was observed only on very few areas of the treated surface (Fig. $2 \mathrm{f}$ as compared to Fig. 2e).

As already described above for the glass composition $\mathbf{A}$, the morphology of precipitates formed by the chemical treatment transformed during the ageing for the glass compositions $\mathbf{S L}$ and $\mathbf{P}$ as well. After a 6-months period of ageing, precipitates rich in $\mathrm{Zn}, \mathrm{O}$ and $\mathrm{N}$, less numerous than prior to the ageing, were identified by SEM-EDX on every treated glass surface. Although their nature could not be clarified, different morphologies and chemical compositions were observed. In particular for the glass composition $\mathbf{P}$, the zinc precipitates appeared deliquescent and possibly contain potassium.

\section{Alteration layer thicknesses}

To compare the reduction of the alteration kinetics with the treatment according to the glass composition, alteration layer thicknesses were measured for the untreated and for the treated glass surfaces after a 3- or 6-months period of ageing. These thicknesses $\mathrm{e}_{a}$, detailed in Table 3, are graphically displayed on Fig. 4. Note that for the alteration layers thick enough to be distinguished by SEM on the edge, the thickness was homogeneous. Like for glass $\mathbf{A}$, a reduction of the alteration layer thickness was measured for the glasses $\mathbf{S L}$ and $\mathbf{P}$ after a 3- or 6-months period of ageing. However, the reduction was less marked than for glass $\mathbf{A}$. For glass $\mathbf{S L}$, the alteration layer of the treated glass plate was about 1.7 time thinner than the untreated one after 3 and 6 months. For glass $\mathbf{P}$, the ratio was around 1.8 after 3 months of ageing and around 2 after 6 months of ageing.

Composition and hydration level of the alteration layers 
After a $\mathrm{V}$ test lasting 6 months, the alteration layers of the treated glasses were not depleted in Ca whatever the glass composition, while the Ca depletion was nearly total for the untreated glass $\mathbf{A}$ and SL, and higher than $50 \%$ for the untreated glass $\mathbf{P}$ (column $\mathrm{Ca} / \mathrm{Si}$ in Table 4 ). For the treated glass plates, the depletion in Na was close to $20 \%, 30 \%$ and $25 \%$ for glasses $\mathbf{A}$, SL and $\mathbf{P}$ respectively (column Na/Si in Table 4). The depletion was similar to the one of the untreated plates for the glass compositions $\mathbf{A}$ and $\mathbf{P}$. On the contrary for glass $\mathbf{S L}$, this depletion was significantly lower than for the untreated glass (which was around $70 \%$ ). As regards K element, no depletion was measured for glass $\mathbf{A}$ and SL, whether untreated or treated (column K/Si in Table 4). For glass $\mathbf{P}$, this depletion was limited and similar for the untreated and the treated glass (around $20 \%$ ).

The hydration levels of the alteration layers for the treated plates, as obtained from these analyses, are $4.8 \%, 2.5 \%$ and $3.2 \%$ for glasses $\mathbf{A}, \mathbf{S L}$ and $\mathbf{P}$ respectively. Thus, they appear lower than the ones calculated for the untreated plates (respectively $9 \%, 8.8 \%$ and $6.2 \%$ for glass $\mathbf{A}$, SL and $\mathbf{P}$ ). This comparison could suggest that the alteration layer was actually less hydrated with the treatment, or that its thickness was inhomogeneous, in which case an overestimation of the alteration layer thickness that would lead to an underestimation of the hydration level has to be considered. However, as stated above, when the observation of the alteration layer glass was possible by SEM observations on the edge (for glass compositions SL and $\mathbf{P}$ ), the thickness of the alteration layers appeared relatively homogeneous for the treated as for the untreated glass plates.

Thus, a benefit of the treatment was observed for the three compositions. This benefit was more marked for glass $\mathbf{A}$ and less for glass $\mathbf{P}$. The depletion of the hydrated layer in $\mathrm{Ca}^{2+}$ ions was suppressed and the depletion in alkali ions was either nearly unchanged $(\mathbf{A}, \mathbf{P})$ or reduced (SL). Overall, the microsctructure and composition of the alteration layers, which were distinct for the 3 glass compositions without the treatment, became more similar with the treatment. This general result reveals that the reactivity of the glass with the atmosphere is significantly controlled by the $\mathrm{Zn}$ species, with a less important role of the 
glass composition.

\subsection{Complementary experiments: effects of the treatment on a previously}

\section{altered surface}

The surface of altered glass objects corresponds to a hydrated layer (up to several hundreds of micrometers for the most advanced stage) that may be fractured vertically and horizontally. ${ }^{1-4,11,39}$ Therefore, next to the study of pristine glass surfaces, it is crucial for the potential application of the treatment in cultural heritage to study the effects of the treatment on a hydrated surface. To this purpose, we have also included a pre-ageing step in some of our experiments, in order to produce hydrated glass surfaces, however not fractured in order to separate the effects between a pristine and a hydrated surface. Indeed, if the hydrated layer were fractured, then the treatment solution would reach the interface with the pristine glass, so that the response of the treatment would be mixed. The choice of the experimental conditions for the pre-ageing step was not at all trivial, as it aimed at replicating the surface of glass objects that aged naturally for centuries - but in a short time. To simulate ambient museum conditions, these accelerated ageing tests were conducted with the lowest ageing temperature of our study $\left(40^{\circ} \mathrm{C}\right)$, at $85 \mathrm{RH} \%$. The maximal duration of the pre-ageing step (3 months) was chosen as a compromise to develop thick hydrated layers without cracking.

After a ZP_1.5 treatment using $\mathrm{Zn}\left(\mathrm{NO}_{3}\right)_{2} \cdot 6 \mathrm{H}_{2} \mathrm{O}$ of these pre-altered surfaces, $\mathrm{Zn}$ (II) was present on the surface mainly as precipitates, the nature of which appeared different to that of non-altered surfaces and could not be clarified. From Tof-SIMS analysis, whether before or after the final ageing step, the penetration of $\mathrm{Zn}^{2+}$ ions into the alteration layer was limited to some tens of $\mathrm{nm}$ (profiles not shown), whatever the alteration layer thickness (from about $0.1 \mu \mathrm{m}$ for a 17 -days ageing up to $1 \mu \mathrm{m}$ for a 3-months ageing - Table 3). Furthermore, the spraying treatment of the pre-altered samples did not show any positive effect on the reduction of the atmospheric alteration kinetics at $40{ }^{\circ} \mathrm{C}, 85 \mathrm{RH} \%$ when evaluated after several periods of ageing (12 or 25 days for a 17-days pre-alteration step - 6 months for

This article is protected by copyright. All rights reserved. 
a 3 months pre-alteration step). Thus, the efficacy of the zinc salt spraying treatment seems strongly influenced by the glass surface state prior to the treatment. We emphasize that these results concerning the treatment of pre-altered glass surfaces cannot be used alone to predict the relevance of a zinc salt treatment for ancient glass objects, considering the differences between these artificial hydrated layers and the "true" surfaces of ancient glass objects in terms of morphology, composition and structure. ${ }^{39}$

\section{DISCUSSION}

This study aims at evaluating a chemical treatment of the glass surface based on zinc salts to slow down the atmospheric alteration of glass. This treatment consists of a deposit of a very small amount of zinc salts. The deposit leads to an almost immediate reaction of the salt with the glass surface. The treatment was shown to have a positive effect on the reduction of the hydration kinetics for the three glass models of the cultural heritage after an accelerated ageing test (at $40^{\circ} \mathrm{C}$ or $80^{\circ} \mathrm{C}$ and $85 \mathrm{RH} \%$ ), and it has other pronounced effects on the nature and distribution of salts on the surface and the composition of the hydrated layer. By contrast with the results of the accelerated ageing tests, no positive effect of the $\mathbf{Z P}_{\text {_ }} \mathbf{1 . 5}$ treatment could be observed for the 2-years ageing experiment in an ambient atmosphere. For glass A in particular, the thickness of the alteration layer of both treated and untreated glass plates is about $150 \mathrm{~nm}$ after the 2-years ageing in an ambient atmosphere. By comparison, when the ageing tests were performed at $40^{\circ} \mathrm{C}, 85 \mathrm{RH} \%$, the reduction of the alteration layer thickness with the treatment was observed for the shortest ageing period already (V17d - Table 3), during which a shorter alteration thickness than $150 \mathrm{~nm}$ developed at the surface of the untreated glass plate. Therefore, if the treatment had an effect at ambient temperature, this effect should have been revealed before reaching $150 \mathrm{~nm}$ for the alteration layer. Considering this lack of performance at low temperature, it seems that the protocol of the treatment needs further improvement and investigation to be relevant for the protection of ancient glasses in museums. In particular, our experimental results suggest that the temperature coud be a 
contributing factor to the activation of the protection. Thus, a moderate heating of the glass artefact (between $40{ }^{\circ} \mathrm{C}$ and $80^{\circ} \mathrm{C}$ ) may be a necessary step in the deposit protocol. This point is investigated together with the speciation of $\mathrm{Zn}$ (II) on glass surface and our related inferences about the mechanisms of the protection by zinc salts in the part II of this study. ${ }^{37}$

A crucial aspect for the treatment relevancy is whether zinc salts would also be efficient on hydrated glass surfaces such as those of glass artefacts in museums. An inherent difficulty to this experimental evaluation is related to the difficulty to work with true cultural artefacts that aged naturally in an indoor atmosphere during centuries. The reproduction of relevant hydrated surfaces in a short time is a fundamental limitation to these experimental studies. It was shown that when the treatment is deposited on our artificial hydrated layers (developed after an ageing at $40^{\circ} \mathrm{C}, 85 \mathrm{RH} \%$, for some days to some months), it does not slow down the hydration kinetics. But the fact that these artificial hydrated layers do not simulate perfectly the surfaces of ancient glass, as suggested by comparative characterisations with a few ancient glass artefacts from museums,${ }^{39}$ does not allow to conclude at this stage. The research must be carried on to work with surfaces that represent as closely as possible natural cases of ageing, including the study of a greater number of ancient glasses and their characterisation at a small scale to better know the characteristics of these altered surfaces.

An advantage of such a treatment compared with the other protective treatments of ancient glasses, namely adherent coatings, is related to the considerably reduced amount of deposited material on the glass surface, in favor of the integrity of the glass artefact. While the thinnest coatings developed in the last decades are about a few hundred nanometers, ${ }^{21-24}$ the quantity of deposited zinc in this study corresponds to a maximum of about $3.3 \mathrm{~nm}$ of $\mathrm{ZnO}$, by assuming an homogeneous layer with a density equal to $5.61 \mathrm{~g} \mathrm{~cm}^{-1}$. Regarding the reversibility, the removal of the zinc treatment, presumably by mild acid washing, appears much less damaging for the glass surface than the removal of the adherent coatings 
(fixed to the glass by siloxane bonds) that requires alkaline solutions, which promote the dissolution of glass. Furthermore, the deposit protocol appears very simple, without prolonged contact with a liquid phase on the contrary to sol-gel processes used for the adherent coatings. Therefore, we think that the deposit of zinc salts is a promising alternative protection treatment, worth of further investigations, notably with protocols including a moderate heating step. As a matter of fact, this study demonstrates the remarkable efficacy of this treatment at $40^{\circ} \mathrm{C}$ or $80^{\circ} \mathrm{C}$ on pristine glass surfaces of three different glass compositions, whatever their initial chemical durability, and the relevancy of its use for modern glasses as it is done in the industrial context with the treatment of the hot surface of float glasses (at $\left.60^{\circ} \mathrm{C}\right)$.

\section{CONCLUSION}

External chemical treatments to slow down the glass atmospheric alteration could be an efficient way to protect glass artefacts of the cultural heritage (glass objects, enamels and glazes). Considering that water is the main reactive agent of this alteration, two chemical approaches at least can be envisaged: [i] coatings that would act as a diffusion barrier towards reactants, notably the water molecules, [ii] chemical agents that would stabilize the glass surface against reaction with water. Our study falls within this second approach. The investigated treatment consists of spraying a solution containing zinc salts on the glass surface, which deposits a very small amount of about 0.1 to about $1.5 \mathrm{\mu g} / \mathrm{cm}^{2} \mathrm{Zn}^{2+}$ ions. The promising advantages of this treatment lie in the very limited deposited amount that preserves the integrity of the artefact and ensures the best chance of reversibility. By carrying out accelerated ageing experiments on three representative glass replicas, this study demonstrates that the treatment is clearly efficient in reducing the hydration layer thickness and the formation of carbonates on the surface of pristine glass at $40{ }^{\circ} \mathrm{C}$ or $80^{\circ} \mathrm{C}$. There is an effect of the glass composition on the treatment efficacy, which varies according to the glass but remains positive. However, there are two conditions that are currently not 
fulfilled by the treatment as proposed for the protection of ancient glasses in museums, so that further improvement and investigations are required. First, the treatment has not shown any obvious efficacy at ambient temperature. Because we found it efficient at $40^{\circ} \mathrm{C}$, it suggests that a moderate heating step after the deposit may be an interesting way of improvement. Second, the treatment was not efficient on the hydrated glass surfaces that we have prepared in this study. This point is the most difficult to address and overcome, because it challenges our ability to reproduce the altered surfaces of the true artefacts of the cultural heritage. More studies on the chemical and microstructural characteristics of these surfaces are necessary to improve our methods of assessing and studying the effects of the treatment. Providing continuation of this research in the aforementioned directions, this treatment represents an interesting and promising new way to protect the glass collections of the cultural heritage.

\section{Acknowledgements}

The authors gratefully thank PSL University for the funding of this work, Marie-Hélène Chopinet, Sophie Papin and Kamila Plevacova (Saint-Gobain Recherche, France) for the glass fabrication. For their skillful assistance during experimental analysis, the authors also thank Sandrine Zanna (IRCP) for XPS measurements, and Claire Pacheco, Brice Moignard, Quentin Lemasson, Laurent Pichon, Thomas Calligaro (C2RMF) for PIXE measurements. Région Ile-de-France is acknowledged for the partial funding of the Tof-SIMS equipment.

\section{References}

${ }^{1}$ Brill RH. Crizzling - a problem in glass conservation. Stud Conserv. 1975;20(Sup1: 1975 Stockholm Congress: Conservation in Archaeology and the Applied Arts):121-134.

${ }^{2}$ Kunicki-Goldfinger JJ. Unstable historic glass: symptoms, causes, mechanisms and conservation. Rev Conserv. 2008;9:47-60. 
${ }^{3}$ Ryan JL. The atmospheric deterioration of glass: studies of decay mechanisms and conservation $[\mathrm{PhD}$ thesis]. Imperial College - University of London; 1995.

${ }^{4}$ Koob SP. Conservation and care of glass objects. New-York: Archetype Publications; 2006.

${ }^{5}$ Biron I, Alloteau F, Lehuédé P, Majérus O, Caurant D, editors. Glass Atmospheric Alteration: Cultural Heritage, Industrial and Nuclear Glasses. Hermann ed. Paris; 2019.

${ }^{6}$ Cobo del Arco B. Survey of the national museums of Scotland glass collection. In: Tennent NH, editor. Conservation of Glass and Ceramics. London: James \& James; 1999. p. 229-238.

${ }^{7}$ Oakley V. Five years on: a reassessment of aspects involved in the consrvation of glass objects for a new gallery at the Victoria and Albert Museum. In: Tennent NH, editor. Conservation of Glass and Ceramics. London: James \& James; 1999. p. 217-228.

${ }^{8}$ Burghout F, Slager M. Cloudy Patches and Misty Glass: Early Signs of Glass Disease? In: Römich H, Van Lookeren K, editors. Recent advances in Glass, Stained-Glass, and Ceramics Conservation. ICOM-CC; 2013. p. 327-329.

${ }^{9}$ Shortland A, Schachner L, Freestone I, Tite M. Natron as a flux in the early vitreous materials industry: Sources, beginnings and reasons for decline. J Archaeol Sci. 2006;33:521-530.

${ }^{10}$ Lagabrielle S. La verrerie du XIIe à la fin du XVe siècle : évolution d'une technique. Médiévales. 2000;19(39):57-78.

${ }^{11}$ Biron I. Émaux sur Métal - du IXe au XIXe Siècle. Histoire, Technique et Matériaux. Faton ed.; 2015.

${ }^{12}$ Bailly M. La conservation-restauration du verre : Bilan et perspective. In: de l'Avesnois É, editor. Conservation, restauration du verre. Actualité et problématiques muséales - Trélon 28 septembre 2007; 2007. p. 59-68.

${ }^{13}$ Organ RM. The safe storage of unstable glass. Museums J. 1957;56(11):255-272. 
${ }^{14}$ Brill RH. The Use of Equilibrated Silica Gel for the Protection of Glass with Incipient Crizzling. J Glass Stud. 1978;20:100-118.

${ }^{15}$ Robinet L. The role of organic pollutants in the alteration of historic soda silicate glasses $[\mathrm{PhD}$ thesis]. Edinburgh - Paris VI; 2006. Available from: https://tel.archives-ouvertes.fr/file/ index/docid/88408/filename/These-LRobinet.pdf.

${ }^{16}$ Oakley V. Fighting the inevitable: the continuing search for a solution to glass decay at the V\&A. Glass Technol. 2001;42(3):65-69.

${ }^{17}$ Errett RF, Lynn M, Brill RH. The use of silanes in glass conservation. In: Adhesives and Consolidants, Preprints of the Contributions to the Paris Congress, 2-8 September 1984. London: The International Institute for Conservation of Historic and Artistic Works; 1984. p. 185-190. Available from: https://www.cmog.org/sites/default/files/collections/9D/ 9D53FB19-F3B9-49F9-8084-9E8E1B814A2C.pdf.

${ }^{18}$ Brinkmann U. CONSTGLASS. Conservation materials for stained glass windows - assessment of treatments, studies on reversibility and performance of innovative restoration strategies and products. Final object report. Part I - IV.; 2010. Available from: http://www.constglass.fraunhofer.de/uploads/media/CONSTGLASS $\left\{\backslash_{-}\right\}$Final $\left\{\backslash_{-}\right\}$object $\left\{\backslash_{-}\right.$ \}report $\left\{\backslash_{-}\right\}$Part $\left\{\backslash_{-}\right\} 1\left\{\backslash_{-}\right\}$of $\left\{\backslash_{-}\right\} 4$.pdfhttp://www.constglass.fraunhof er.de/uploads/ media/CONSTGLASS $\left\{\backslash_{-}\right\}$Final $\left\{\backslash_{-}\right\} \operatorname{object}\left\{\backslash_{-}\right\} \operatorname{report}\left\{\backslash_{-}\right\} \operatorname{Part}\left\{\backslash_{-}\right\} 2\left\{\backslash_{-}\right\} \operatorname{of}\left\{\backslash_{-}\right\} 4$.pdfhttp: //www. constglass.fraunhofer.de/uploads/media/CONSTGLASS $\left\{\backslash_{-}\right\}$.

${ }^{19}$ Newton RG, Seddon B. Organic coatings for medieval glass. In: Tennent NH, editor. The conservation of glass and ceramics. London: James \& James; 1999. p. 66-71.

${ }^{20}$ Hogg SET, McPhail DS, Oakley V. Mono-functional organosilanes as candidates for treatments of crizzling in glasses. In: Paterakis AB, editor. Interim Meeting of the ICOM-CC Ceramics, Glass and

This article is protected by copyright. All rights reserved. 
Related Materials Working Group. Vantaa, Finland: EVTEK Institute of Arts and Design; 1998. p. $53-57$.

${ }^{21}$ Necaskova M. Conservation Treatment of the Last Judgment Mosaïc. In: Ball T, editor. Conservation of the Last Judgment Mosaï, St Vitus Cathedral, Prague. Los Angeles: The Getty Conservation Institute; 2004. p. 211-222.

${ }^{22}$ Dal Bianco B, Bertoncello R, Bouquillon A, Dran JC, Milanese L, Roehrs S, et al. Investigation on sol-gel silica coatings for the protection of ancient glass: Interaction with glass surface and protection efficiency. J Non-Cryst Solids. 2008;354(26):2983-2992.

${ }^{23}$ De Bardi M, Hutter H, Schreiner M, Bertoncello R. Sol-gel silica coating for potash-lime-silica stained glass: Applicability and protective effect. J Non-Cryst Solids. 2014;390:45-50.

${ }^{24}$ Holubová B, Cílová ZZ, Kučerová I, Zlámal M. Weatherability of hybrid organic-inorganic silica protective coatings on glass. Prog Org Coat. 2015;88:172-180.

${ }^{25}$ Rullier R. Procédé de Traitement des Surfaces de Verre. Patent FR 2269500A1; 1975.

${ }^{26}$ Lewchuk R, Moser F. Treatment of glass surfaces. Patent CA 770571 A; 1967.

${ }^{27}$ Chopinet MH, Lehuédé P. Les problèmes d'altération rencontrés sur des verres industriels. Verre. 2010;16:20-27.

${ }^{28}$ Emonds M, Villari V. Protective coating of float glass by liquid anti- corrosion systems. Glass Performance Days. 2009:649-653. Available from: www.gpd.fi.

${ }^{29}$ Nunes de Carvalho J, Cleaver JAS, Kirkby NF, Holmes PA. An experimental study of the effect of zinc treatment on float glass. Glass Technol-Part A. 2014;55(1):14-22.

${ }^{30}$ Berger PS, Song BX, Schwartz JR, Corkery RW. Zinc corrosion protection agents for treating glassware surfaces. Patent US 7094740 B2; 2006. 
${ }^{31}$ Caravajal GS. Rinse additive compositions providing glassware protection. Patent EP 0383480A1; 1990.

${ }^{32}$ Keyes G, Seaman B, Kassen J. Liquid automatic dishwashing composition with glass ware protection. Patent US 6448210; 2002.

${ }^{33}$ Eiting T, Mussman N, Bastigkeit T, Benda K, Kessler A, Maisey C, et al.. Dishwashing detergents with improved protection of decoration. Patent WO 2012175292 A1; 2012.

${ }^{34}$ Verità M. Modern and ancient glass: nature, composition and deterioration mechanisms. In: Lefèvre RA, editor. The Materials of Cultural Heritage in their Environment. edipuglia ed. Bari; 2006. p. $119-132$.

${ }^{35}$ Iliffe CJ, Newton RG. Using Triangular Diagrams To Understand the Behaviour of Medieval Glasses. Verres Refract. 1976;30(1):30-34.

${ }^{36}$ Alloteau F, Majérus O, Biron I, Lehuédé P, Caurant D, Charpentier T, et al. Temperaturedependent mechanisms of the atmospheric alteration of a mixed-alkali lime silicate glass. Corros Sci. 2019;159:108129.

${ }^{37}$ Alloteau F, Majérus O, Valbi V, Biron I, Lehuédé P, Caurant D, et al. Efficacy of zinc salts to protect glass against atmospheric alteration. Part II: Possible passivation mechanisms. submitted to J Am Ceram Soc.

${ }^{38}$ Alloteau F, Valbi V, Majérus O, Biron I, Lehuédé P, Caurant D, et al. Alteration mechanisms of ancient glass objects exposed to the atmosphere. In: Biron I, Alloteau F, Lehuédé P, Majérus O, Caurant D, editors. Glass Atmospheric Alteration - Cultural Heritage, industrial and Nuclear Glasses. Paris: Hermann; 2019. p. 13-24.

${ }^{39}$ Alloteau F. Contribution à la compréhension des mécanismes de l'altération atmosphérique des verres et étude d'un traitement de protection à base de sels de zinc [PhD thesis]. PSL Research University; 2017. Available from: https://hal.archives-ouvertes.fr/tel-01703276/document. 
${ }^{40}$ Alloteau F, Lehuédé P, Majérus O, Biron I, Dervanian A, Charpentier T, et al. New insight into atmospheric alteration of alkali-lime silicate glasses. Corros Sci. 2017;122:12-25.

${ }^{41}$ Greenspan L. Humidity fixed points of binary saturated aqueous solutions. J Res NBS A Phy Ch. $1977 ; 81 \mathrm{~A}(1): 89$.

\section{LIST OF FIGURES WITH LEGENDS}

Figure 1: Optical images of the surface of glass A plates several days after a $\mathrm{V}$ test $\left(80^{\circ} \mathrm{C}, 85 \mathrm{RH} \%\right.$, for 3 days). (a) untreated, $\mathrm{e}_{a}=13 \pm 1 \mu \mathrm{m}$. (b) $\mathbf{Z P} \_$1.5-treated $\left(\mathrm{Zn}_{5}(\mathrm{OH})_{8}\left(\mathrm{NO}_{3}\right)_{2} \cdot 2 \mathrm{H}_{2} \mathrm{O}\right)$ prior to the $\mathrm{V}$ test, $\mathrm{e}_{a}=0.21 \pm 0.02 \mu \mathrm{m} . \mathrm{e}_{a}$ : alteration layer thickness.

Figure 2: SEM images of glass plate surfaces (a), (b) A, (c), (d) $\mathbf{S L}$ or (e), (f) $\mathbf{P}$ after a $\mathrm{V}$ test $\left(40^{\circ} \mathrm{C}\right.$, $85 \mathrm{RH} \%$, for 6 months), either untreated - (a), (c), (e) - or treated - (b), (d), (f) - with the ZP_1.5 treatment $\left(\mathrm{Zn}_{5}(\mathrm{OH})_{8}\left(\mathrm{NO}_{3}\right)_{2} \cdot 2 \mathrm{H}_{2} \mathrm{O}\right)$ prior to the $\mathrm{V}$ test. Phases numbered 1 and 4: Na-carbonates, numbered 2: Ca-carbonate, numbered 3, 6 and 8: Zn, N, O-rich, numbered 5: silica. Numbered 7: thin continous layer of precipitates (nature unidentified).

Figure 3: Comparison of the alteration layer thicknesses $\left(\mathrm{e}_{a}\right)$ of untreated or $\mathbf{Z P} \_\mathbf{1 . 5}$-treated glass plates A as a function of the ageing period $\left(\mathrm{V}\right.$ tests at $\left.80^{\circ} \mathrm{C}, 85 \mathrm{RH} \%\right)$. The corresponding numerical values are reported in Table 2 .

Figure 4: Comparison of the alteration layer thicknesses $\left(\mathrm{e}_{a}\right)$ with or without a $\mathrm{ZP} \_1.5$ treatment for the 3 glass compositions after a $\mathrm{V}$ test at $40{ }^{\circ} \mathrm{C}, 85 \mathrm{RH} \%$ for 3 months (V3m) or for 6 months (V6m). The corresponding numerical values are reported in Table 3. 


\section{TABLES WITH LEGENDS}

$$
\begin{array}{llllll}
\mathrm{SiO}_{2} & \mathrm{Al}_{2} \mathrm{O}_{3} & \mathrm{MgO} & \mathrm{CaO} & \mathrm{Na}_{2} \mathrm{O} & \mathrm{K}_{2} \mathrm{O}
\end{array}
$$

\section{SL: Soda Lime Silicate}

From Antiquity

$\begin{array}{lllll}66.8 & 2.5 & 3.0 & 7.5 & 18.0\end{array}$

2.1

coastal plants

\begin{tabular}{|c|c|c|c|c|c|c|}
\hline Middle-Age, Renaissance, 19th century & 71.0 & 0.8 & 0.8 & 5.0 & 11.0 & 11.0 \\
\hline $\begin{array}{l}\text { purified ashes of plants with tartar or } \\
\text { salpetre salt }\end{array}$ & & & & & & \\
\hline P: Potassium Silicate & & & & & & \\
\hline 16th, 17th, 18th centuries & 75.8 & 0.3 & 0.2 & 2.0 & 1.5 & 20.2 \\
\hline
\end{tabular}

Table 1: Nominal composition of glass replicas (weight\%), from ancient glass compositions with their production periods and main sources of alkalis.

This article is protected by copyright. All rights reserved. 


\begin{tabular}{|c|c|c|c|c|c|c|c|c|c|c|c|c|c|}
\hline & $\mathrm{e}_{a}(\mu \mathrm{m})$ & $\mathrm{O}$ & $\mathrm{Na}$ & $\mathrm{Mg}$ & $\mathrm{Al}$ & $\mathrm{Si}$ & $\mathrm{K}$ & $\mathrm{Ca}$ & $\begin{array}{c}\text { calculated } \\
\mathrm{O}\end{array}$ & $\frac{\mathrm{Na}}{\mathrm{Si}}$ & $\frac{\mathrm{K}}{\mathrm{Si}}$ & $\frac{\mathrm{Ca}}{\mathrm{Si}}$ & $\begin{array}{c}\mathrm{HL}^{1} \\
(\mathrm{wt} \%)\end{array}$ \\
\hline pristine & & 59.5 & 7.6 & 0.4 & 0.3 & 25.2 & 5.0 & 1.9 & 59.5 & 0.30 & 0.20 & 0.075 & - \\
\hline untreated - V1d ${ }^{2}$ & $1.5 \pm 0.5$ & 63.2 & 5.7 & 0.4 & 0.3 & 23.5 & 4.7 & 2.1 & 55.1 & 0.24 & 0.20 & 0.09 & 6.9 \\
\hline \multicolumn{14}{|l|}{$\mathrm{ZP} \_1.5$-treated } \\
\hline (chloride) - V1d & $0.15 \pm 0.02^{3}$ & 63.6 & 5.4 & 0.5 & 0.3 & 23.9 & 4.1 & 2.1 & 55.8 & 0.23 & 0.17 & 0.09 & 6.7 \\
\hline \multicolumn{14}{|l|}{$\mathrm{ZP} \_1.5$-treated } \\
\hline (nitrate) - V1d & $0.14 \pm 0.02^{3}$ & 63.4 & 5.2 & 0.5 & 0.3 & 24.4 & 4.5 & 1.6 & 56.2 & 0.21 & 0.18 & 0.065 & 6.2 \\
\hline \multicolumn{14}{|l|}{ ZP_1.5-treated - } \\
\hline (chloride) - V3d & $0.21 \pm 0.02^{3}$ & 63.7 & 5.0 & 0.4 & 0.3 & 24.4 & 4.6 & 1.5 & 56.0 & 0.21 & 0.19 & 0.06 & 6.6 \\
\hline \multicolumn{14}{|l|}{ ZP1_1.5-treated } \\
\hline (chloride) - V6d & $0.35 \pm 0.1$ & 63.6 & 4.8 & 0.4 & 0.3 & 24.7 & 4.2 & 1.9 & 56.8 & 0.19 & 0.17 & 0.075 & 5.8 \\
\hline
\end{tabular}

Table 2: EDX average compositions (atom\% element with 100\% normalization) of the alteration layers of glass plates $\mathbf{A}$ untreated or treated, and aged $\left(80^{\circ} \mathrm{C}, 85 \mathrm{RH} \%\right.$, various time periods), after EDX measurements at $10 \mathrm{kV}$ or $7 \mathrm{kV}$ accelerating voltage and quantification using a model of stacked layers in the STRATAGem software. ${ }^{1}$ Average hydration level of the alteration layer in weight\%, estimated from the comparison between the oxygen atomic fraction analysed by EDX and the one calculated by stoichiometry (calculated O column). ${ }^{2}$ Analysis performed 48 days after the end of the accelerated ageing of the glass plate, when its surface was still modifying under ambient atmosphere with the appearance and growing of sodium carbonates. ${ }^{40}$ The alteration layer thickness $\left(\mathrm{e}_{a}\right)$, as determined by SEM observations or $\left({ }^{3}\right)$ from Tof-SIMS profiles, is given in the second column. 


\begin{tabular}{|c|c|c|c|c|c|c|c|}
\hline & & $\mathbf{A}$ & A treated & SL & SL treated & $\mathbf{P}$ & $\mathbf{P}$ treated \\
\hline \multirow{3}{*}{$\mathrm{e}_{\mathrm{a}}(\mu \mathrm{m})$} & V17d & $0.11 \pm 0.01$ & $0.07 \pm 0.01$ & - & - & - & - \\
\hline & V3m & $1 \pm 0.2$ & $0.12 \pm 0.02 *$ & $0.15 \pm 0.02 *$ & $0.09 \pm 0.02 *$ & $1 \pm 0.2$ & $0.55 \pm 0.05 *$ \\
\hline & V6m & $2.5 \pm 0.2$ & $0.2 \pm 0.02$ & $0.35 \pm 0.1$ & $0.2 \pm 0.02$ & $2 \pm 0.2$ & $1 \pm 0.2$ \\
\hline
\end{tabular}

Table 3: Alteration layer thickness $\left(\mathrm{e}_{a}\right)$ of untreated or $\mathbf{Z P} \_$1.5-treated glass plates $\mathbf{A}, \mathbf{S L}$ or $\mathbf{P}$ developped with $\mathrm{V}$ tests $\left(40^{\circ} \mathrm{C}, 85 \mathrm{RH} \%\right)$ of various ageing periods, as determined by SEM observations or $\left(^{*}\right)$ from Tof-SIMS profiles. The error bars were determined from the uncertainty on the position of the interface (Tof-SIMS) or from the analysis of multiple areas (SEM). 


\begin{tabular}{|c|c|c|c|c|c|c|c|c|c|c|c|c|c|}
\hline & $\mathrm{e}_{a}(\mu \mathrm{m})$ & $\mathrm{O}$ & $\mathrm{Na}$ & $\mathrm{Mg}$ & $\mathrm{Al}$ & $\mathrm{Si}$ & $\mathrm{K}$ & $\mathrm{Ca}$ & $\begin{array}{c}\text { calculated } \\
\mathrm{O}\end{array}$ & $\frac{\mathrm{Na}}{\mathrm{Si}}$ & $\frac{\mathrm{K}}{\mathrm{Si}}$ & $\frac{\mathrm{Ca}}{\mathrm{Si}}$ & $\begin{array}{c}\mathrm{HL}^{1} \\
(\mathrm{wt} \%)\end{array}$ \\
\hline A pristine & & 59.5 & 7.6 & 0.4 & 0.3 & 25.2 & 5.0 & 1.9 & 59.5 & 0.30 & 0.20 & 0.075 & - \\
\hline $\mathbf{A}-\mathrm{V} 6 \mathrm{~m}$ & $2.5 \pm 0.2$ & 64.4 & 5.9 & 0.6 & 0.3 & 23.6 & 5.1 & 0.1 & 53.8 & 0.25 & 0.21 & 0.004 & 9 \\
\hline $\mathrm{A} Z \mathrm{ZP} \_1.5-\mathrm{V} 6 \mathrm{~m}$ & $0.2 \pm 0.02$ & 62.8 & 5.3 & 0.4 & 0.3 & 24.9 & 4.6 & 1.6 & 57.2 & 0.21 & 0.18 & 0.07 & 4.8 \\
\hline SL pristine & & 58.5 & 12.1 & 1.6 & 1.0 & 23.1 & 0.9 & 2.8 & 58.5 & 0.52 & 0.04 & 0.12 & - \\
\hline SL - V6m & $0.35 \pm 0.1$ & 66.9 & 3.7 & 2.2 & 0.9 & 25.7 & 0.5 & 0.1 & 57.1 & 0.14 & 0.02 & 0.004 & 8.8 \\
\hline SL ZP_1.5 - V6m & $0.2 \pm 0.02$ & 61.2 & 8.7 & 1.5 & 1.0 & 23.8 & 1.0 & 2.8 & 58.2 & 0.37 & 0.04 & 0.12 & 2.5 \\
\hline $\mathbf{P}$ pristine & & 61.2 & 1.0 & 0.1 & 0.1 & 27.4 & 9.3 & 0.8 & 61.2 & 0.04 & 0.34 & 0.03 & - \\
\hline $\mathbf{P}-\mathrm{V} 6 \mathrm{~m}$ & $2 \pm 0.2$ & 65.0 & 0.8 & 0.1 & 0.1 & 26.6 & 7.1 & 0.3 & 57.7 & 0.03 & 0.27 & 0.01 & 6.2 \\
\hline $\mathbf{P} \mathrm{ZP} \_1.5-\mathrm{V} 6 \mathrm{~m}$ & $1 \pm 0.2$ & 63.4 & 0.9 & 0.1 & 0.1 & 27.2 & 7.6 & 0.7 & 59.6 & 0.03 & 0.28 & 0.03 & 3.2 \\
\hline
\end{tabular}

Table 4: EDX average compositions (atom\% element with $100 \%$ normalization) of the alteration layers of glass plates A, SL and $\mathbf{P}$, untreated or treated, and aged $\left(40^{\circ} \mathrm{C}, 85 \mathrm{RH} \%\right.$, for 6 months), after EDX measurements at $7 \mathrm{kV}$ or $15 \mathrm{kV}$ accelerating voltage and quantification using a model of stacked layers in the STRATAGem software. ${ }^{1}$ Average hydration level of the alteration layer in weight\%, estimated from the comparison between the oxygen atomic fraction analysed by EDX and the one calculated by stoichiometry (calculated O column). 

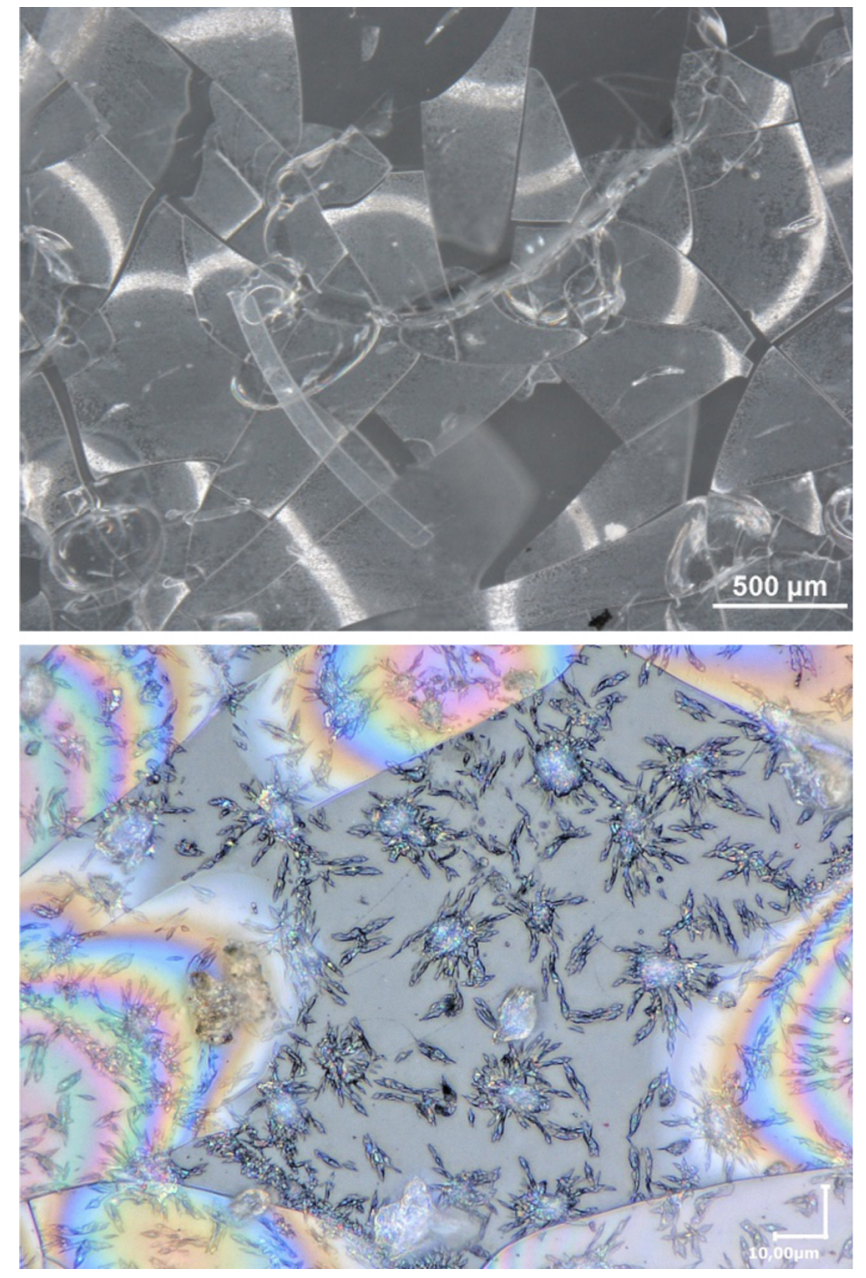

jace_17590_f1a.jpg 

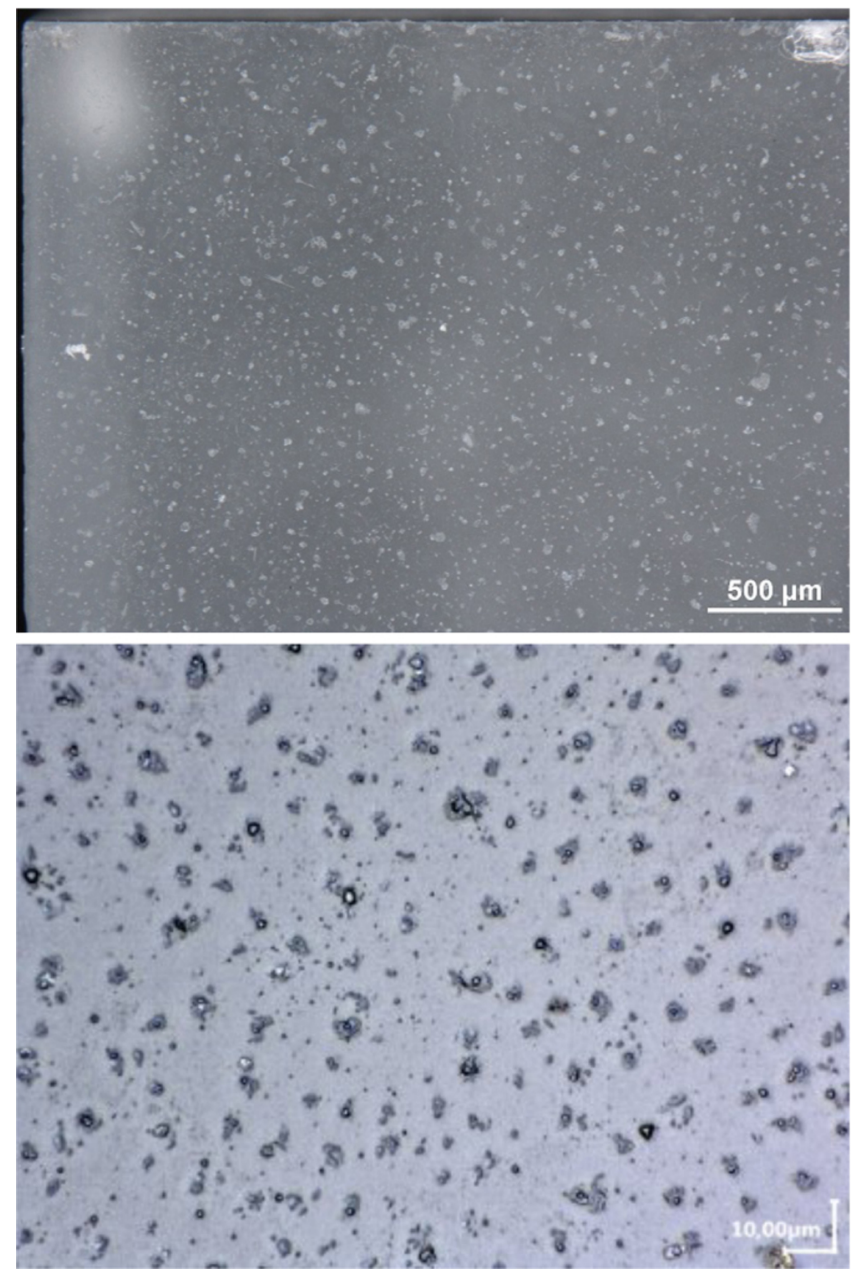

jace_17590_f1b.jpg 


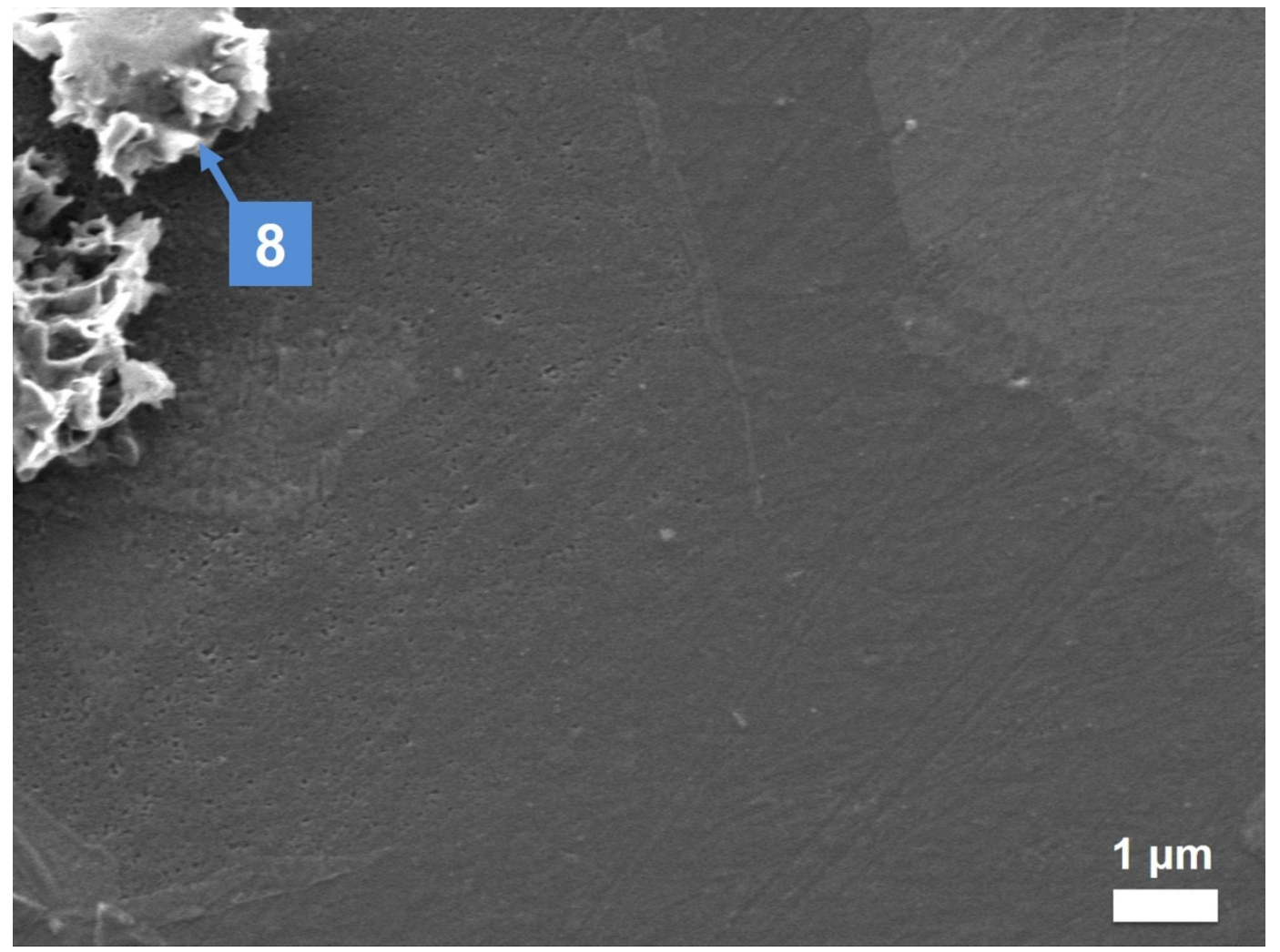

jace_17590_f2.jpg 


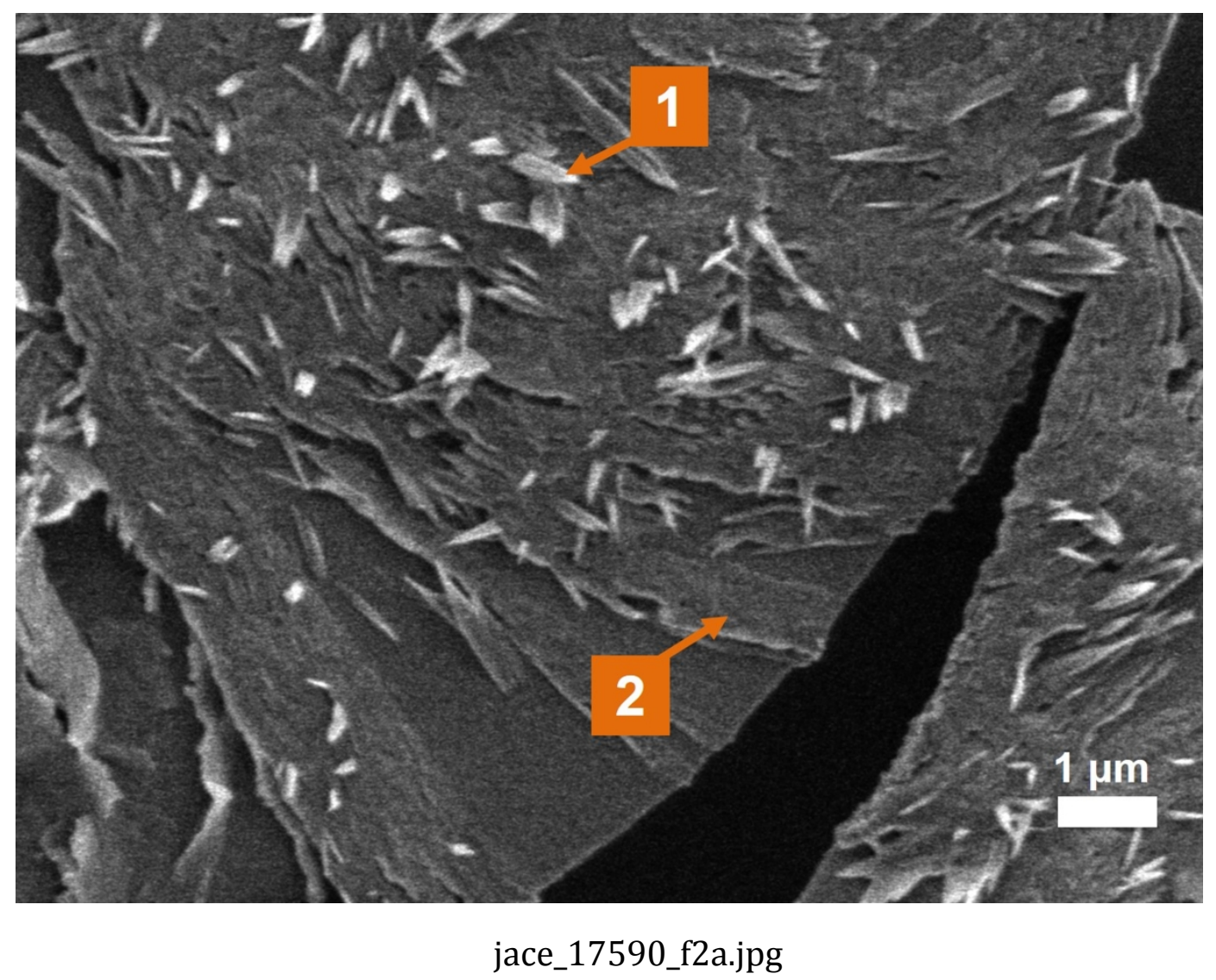

This article is protected by copyright. All rights reserved 


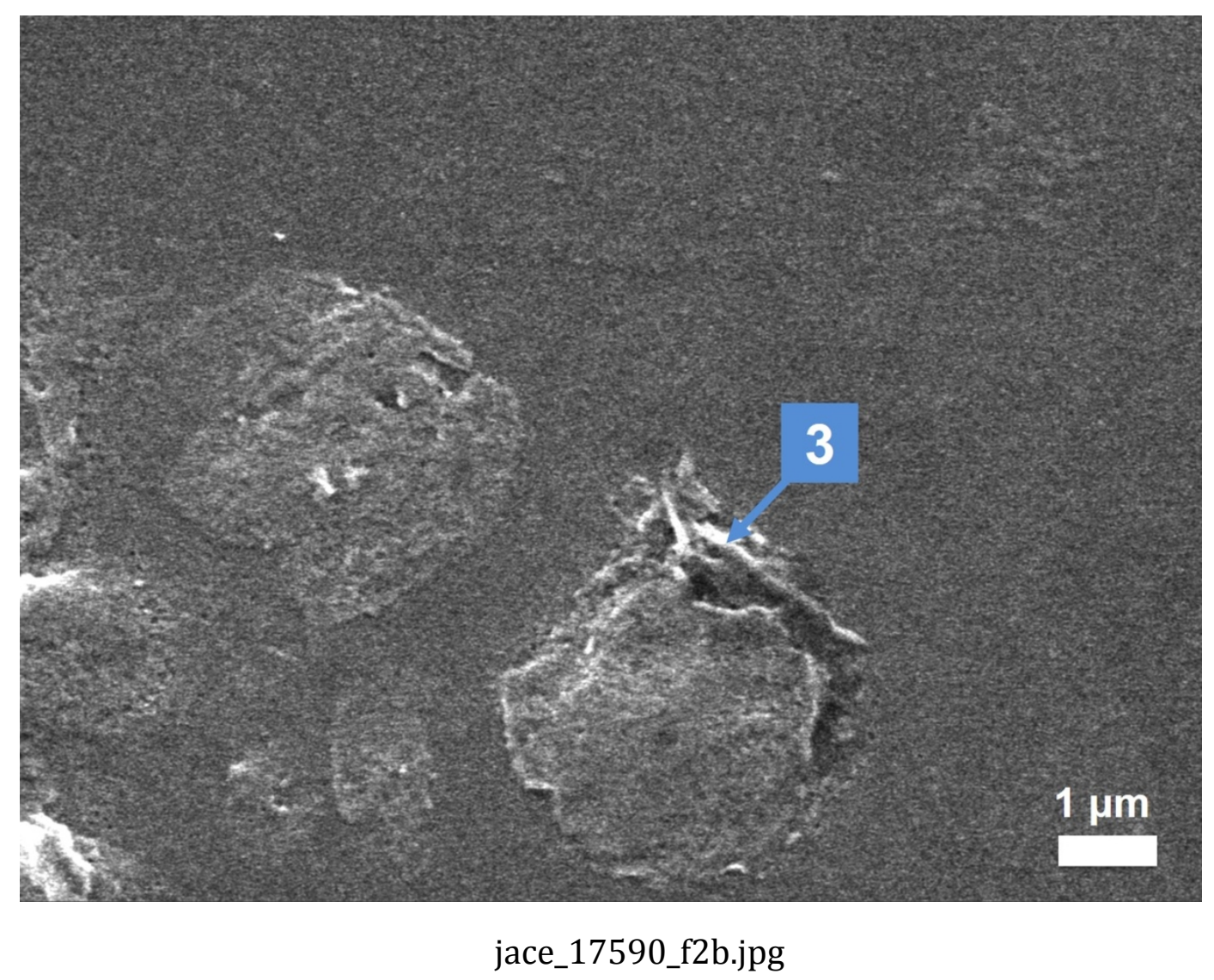

This article is protected by copyright. All rights reserved 


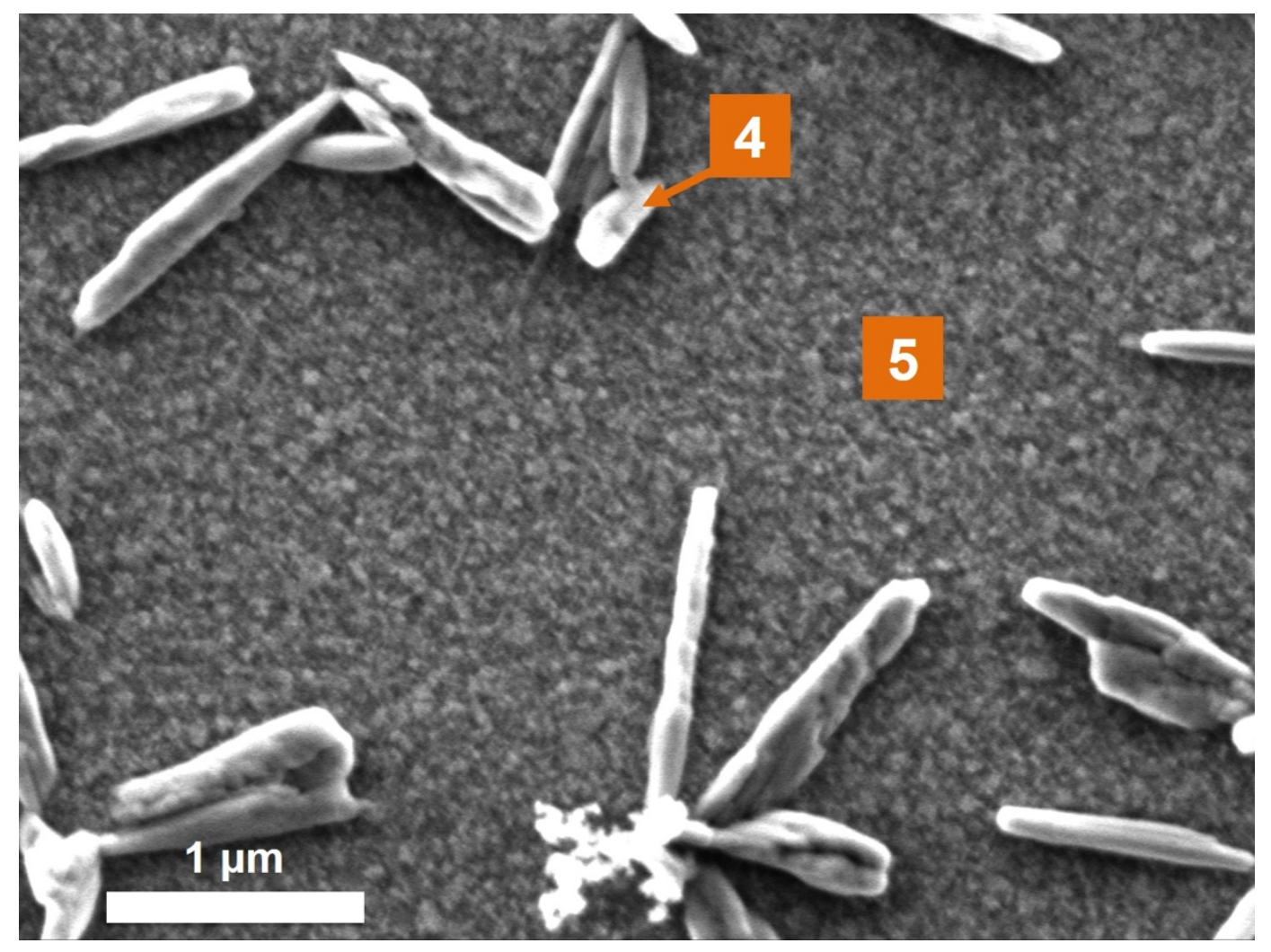

jace_17590_f2c.jpg

This article is protected by copyright. All rights reserved 


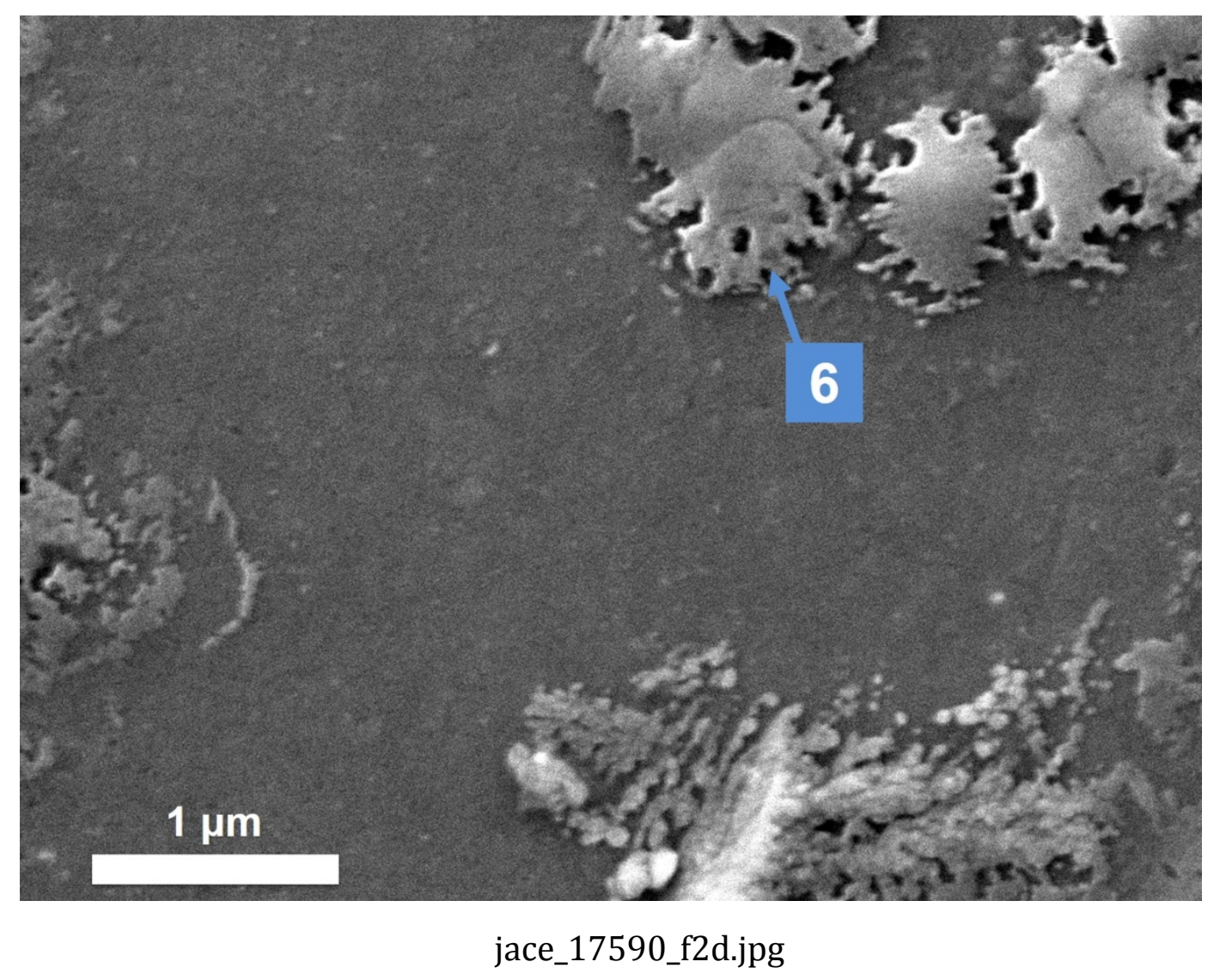

This article is protected by copyright. All rights reserved 


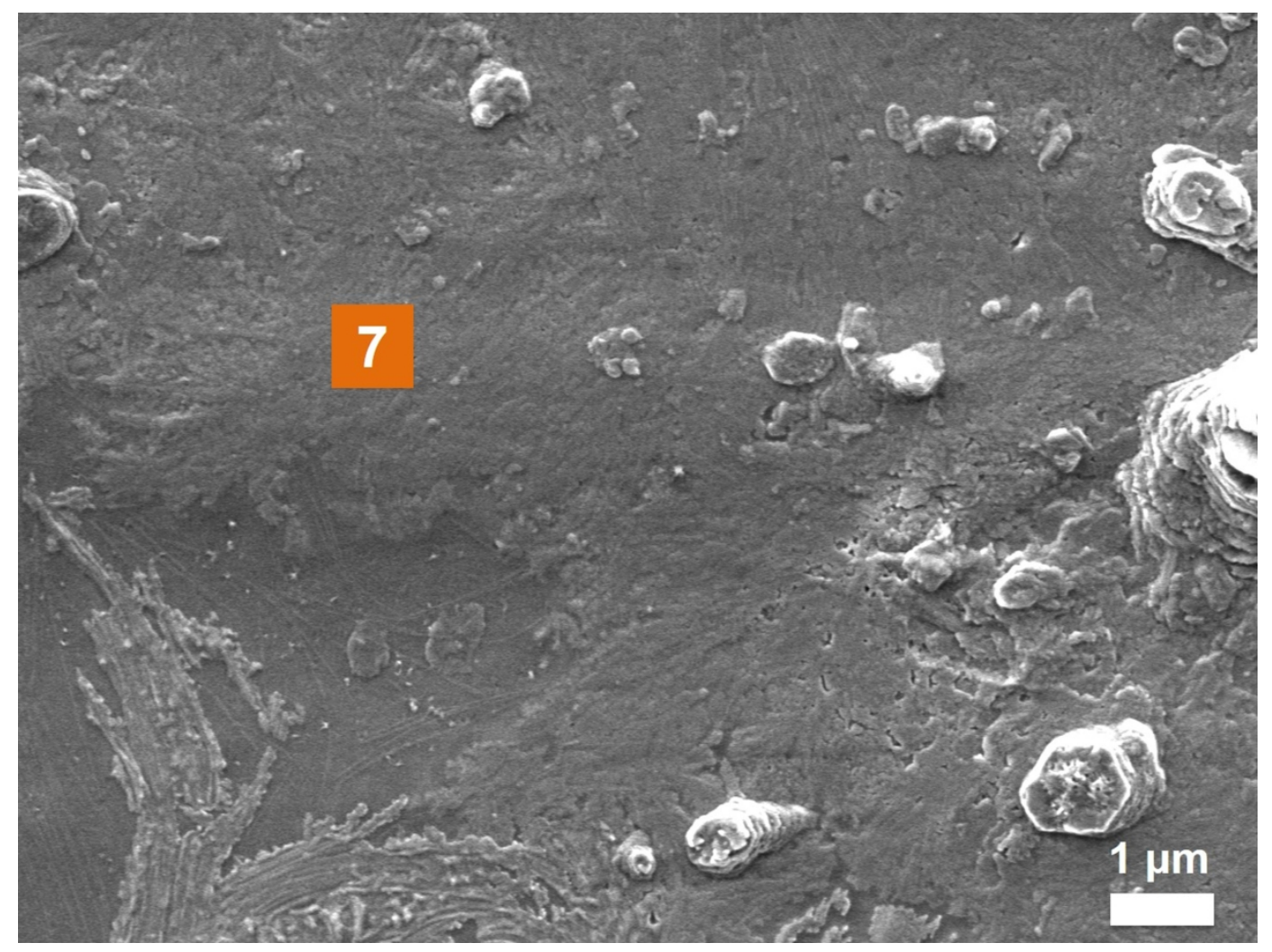

jace_17590_f2e.jpg 


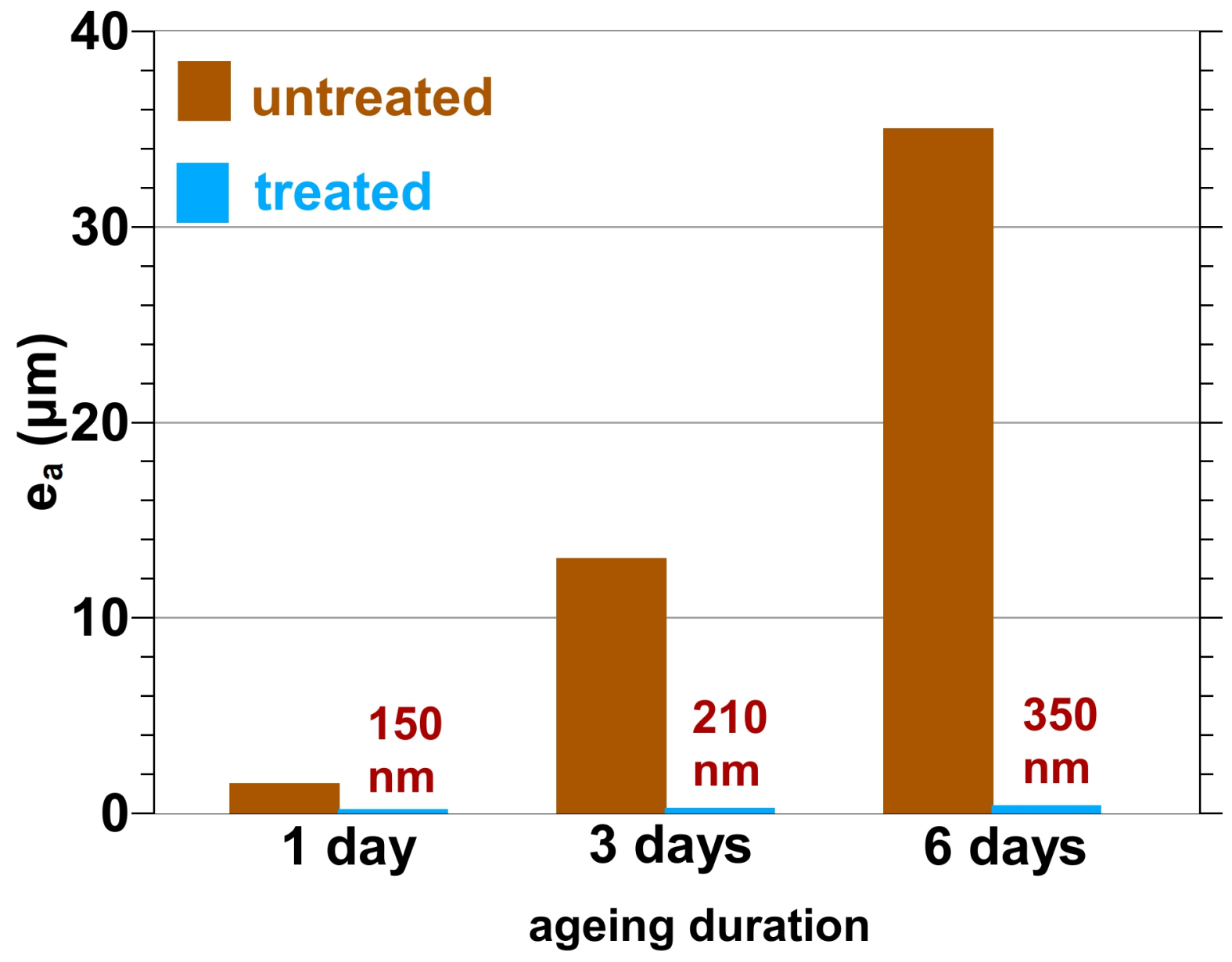

jace_17590_f3.jpg 


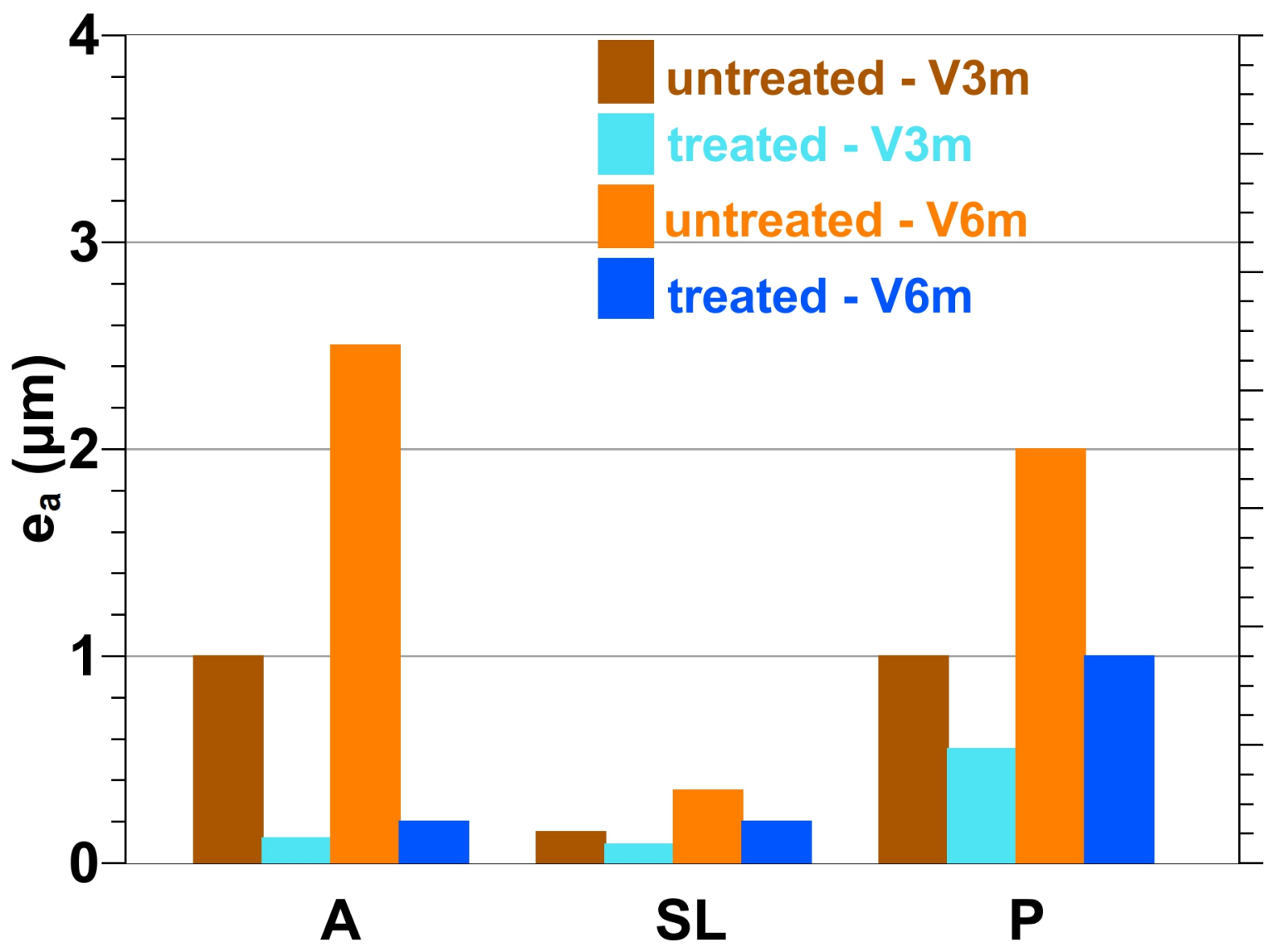

jace_17590_f4.jpg 